\title{
Peripheral Nerve Regeneration and NGF-Dependent Neurite Outgrowth of Adult Sensory Neurons Converge on STAT3 Phosphorylation Downstream of Neuropoietic Cytokine Receptor gp130
}

\author{
Serena Quarta, ${ }^{1}$ Bastian E. Baeumer, ${ }^{2}$ Nadja Scherbakov, ${ }^{1,4}$ Manfred Andratsch, ${ }^{1}$ Stefan Rose-John, ${ }^{5}$ Georg Dechant, ${ }^{3}$ \\ Christine E. Bandtlow, ${ }^{2}$ and Michaela Kress ${ }^{1}$ \\ ${ }^{1}$ Divisions of Physiology, and ${ }^{2}$ Neurobiochemistry, and ${ }^{3}$ Institute of Neuroscience, Medical University Innsbruck, A-6020, Austria, ${ }^{4}$ Centre for Stroke \\ Research Berlin, Charite-Universitätsmedizin, Campus Virchow, D-10117 Berlin, Germany, and ${ }^{5}$ Department of Biochemistry, Christian-Albrechts- \\ University, D-24098 Kiel, Germany
}

After nerve injury, adult sensory neurons can regenerate peripheral axons and reconnect with their target tissue. Initiation of outgrowth, as well as elongation of neurites over long distances, depends on the signaling of receptors for neurotrophic growth factors. Here, we investigated the importance of gp130, the signaling subunit of neuropoietic cytokine receptors in peripheral nerve regeneration.

After sciatic nerve crush, functional recovery in vivo was retarded in SNS-gp130 ${ }^{-1-}$ mice, which specifically lack $g p 130$ in sensory neurons. Correspondingly, a significantly reduced number of free nerve endings was detected in glabrous skin from $S N S$ - $g p 130^{-I-}$ compared with control mice after nerve crush. Neurite outgrowth and STAT3 activation in vitro were severely reduced in cultures in gp130-deficient cultured neurons. Surprisingly, in neurons obtained from SNS-gp130 ${ }^{-I-}$ mice the increase in neurite length was reduced not only in response to neuropoietic cytokine ligands of gp130 but also to nerve growth factor (NGF), which does not bind to gp130containing receptors. Neurite outgrowth in the absence of neurotrophic factors was partially rescued in gp130-deficient neurons by leptin, which activates STAT3 downstream of leptic receptor and independent of gp130. The neurite outgrowth response of gp130deficient neurons to NGF was fully restored in the presence of leptin.

Based on these findings, gp130 signaling via STAT3 activation is suggested not only to be an important regulator of peripheral nerve regeneration in vitro and in vivo, but as determining factor for the growth promoting action of NGF in adult sensory neurons.

Key words: cytokines; gp130; NGF; PNS; regeneration; STAT3

\section{Introduction}

Target reinnervation and functional regeneration after injury regularly occurs in the peripheral nervous system (PNS) in contrast to the CNS which lacks the ability to regenerate. Cytokines and neurotrophins are secreted when local inflammation develops upon peripheral nerve injury and promote axon outgrowth and remyelination (Gaudet et al., 2011; Bosse, 2012).

Of particular relevance for axonal regeneration appears to be the neuropoietic cytokines/interleukin-6 (IL-6) family. Members

Received March 20, 2013; revised July 18, 2014; accepted July 19, 2014.

Author contributions: S.Q. and M.K. designed research; S.Q., B.E.B., N.S., and M.A. performed research; S.R.-J. contributed unpublished reagents/analytic tools; S.Q., B.E.B., and N.S. analyzed data; S.Q., S.R.-J., G.D., C.E.B., and M.K. wrote the paper.

This work was supported by the Austrian Research Funding Agency FWF (Grant P18444 to M.K. and the DKSPIN), Tiroler Wissenschaftsfonds (TWF), and Integriertes Forschungs- und Therapiezentrum (IFTZ). We thank K. Braun and M. Doblander for expert technical assistance, and G. Göbel for statistical support.

The authors declare no competing financial interests.

This article is freely available online through the J Neurosci Author Open Choice option.

Correspondence should be addressed to Dr Michaela Kress, Division of Physiology, DPMP, Medical University Innsbruck, Fritz-Pregl-Str. 3, 6020 Innsbruck, Tiro A-6020, Austria. E-mail: michaela.kress@i-med.ac.at.

DOI:10.1523/JNEUROSCI.1209-13.2014

Copyright $\odot 2014$ the authors $\quad 0270-6474 / 14 / 3413222-12 \$ 15.00 / 0$ of the family, which includes IL-6 itself, ciliary neurotrophic factor (CNTF), and leukemia inhibitory factor (LIF), are upregulated after injury. The activity of neuropoietic cytokines has been associated not only with the control of innate immunity and activation of Schwann cells but also with cell survival, differentiation and axonal regeneration of neurons in the CNS and PNS (Saadat et al., 1989; Kopf et al., 1994; Murphy et al., 1995; Hirota et al., 1996; März et al., 1997, 1998; Sendtner et al., 1997; Zhong et al., 1999; Cafferty et al., 2001, 2004; Shuto et al., 2001; Cao et al., 2006; Wilms et al., 2007; Lara-Ramirez et al., 2008; Spooren et al., 2011; Smith et al., 2012; Zigmond, 2012). This qualifies neuropoietic cytokines as potentially important regulators of axonal regeneration also after nerve lesion.

Neuropoietic cytokines bind to membrane-bound or soluble receptors as factor-specific $\alpha$ receptor subunits (Heinrich et al., 2003; Jones et al., 2011). Importantly they signal through a single transmembrane protein- $\beta$ subunit, the glycoprotein gp130. Therefore by targeting the ubiquitously expressed gp 130, signaling of most neuropoietic cytokines can effectively be prevented (Hibi et al., 1990; Heinrich et al., 2003; Ernst and Jenkins, 2004). gp130 drives cellular responses by association and activation of 
A

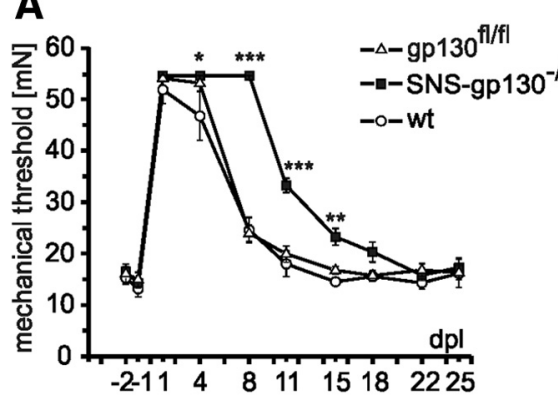

B

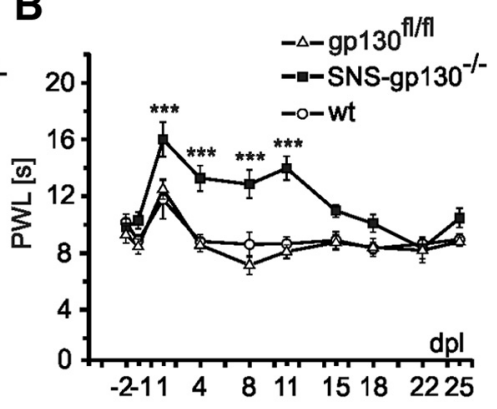

the recommendations of the International Association for the Study of Pain (IASP) to minimize animal suffering (Zimmermann, 1983).

Mouse strains and surgical procedure. Male mice wild-type, $g p 130^{f l f l}$, and SNS- $g p 130^{-1-}$ mice, (aged between 8 and 12 weeks) were used in all experiments. The mutated alleles were backcrossed to C57BL/6J for at least 12 generations and littermates were used for controls. Animals were housed on a $12 \mathrm{~h}$ light/dark cycle with ad libitum access to chow and water (Andratsch et al., 2009).

For setting the crush injury, mice were briefly anesthetized with a Ketasol (Graeub) and xylasol (AniMedica) intraperitoneal injection and the sciatic nerve was crushed perpendicular, at mid-thigh level, for 1 min using a semielectric forceps applying a standard force of $19 \pm 1.8 \mathrm{~N}$ (modified Bioseb Rodent pincher RP-1; De Koning et al., 1986). Mice were allowed to habituate for $1 \mathrm{~h}$ before sensory testing and were maintained at individual cages for the entire duration of $25 \mathrm{~d}$ postlesion $(\mathrm{dpl})$.

Behavioral testing. Mechanical or heat sensitivity following nerve lesion was quantified by standard testing procedures (Andratsch et al., 2009; Quarta et al., 2011). The plantar side of the hindpaw was tested and baseline measurements were taken two times before injury and thereafter repeatedly up to $25 \mathrm{dpl}$. Calibrated von Frey monofilaments with bending forces between 2.8 and $45.3 \mathrm{mN}$ were applied at the plantar surface of the hindpaw. Mechanical sensitivity was determined by measuring the paw withdrawal threshold in response to the stimulus. The withdrawal threshold was determined by increasing and decreasing stimulus

Janus kinases (JAK) and consequent phosphorylation of signal transducers and activators of transcription (STAT) and MAP kinases (Liu and Snider, 2001; Waetzig et al., 2006; Dziennis and Alkayed, 2008; Tedeschi, 2011). Therefore there is an overlap of signaling mechanisms between neuropoietic cytokines and the neurotrophins (Levi-Montalcini, 1952, 1987; Skaper, 2008). The neurotrophins nerve growth factor (NGF), brain-derived neurotrophic factor (BDNF), and neurotrophin 3 (NT3) stimulate neurite outgrowth of sensory neurons by specific receptor tyrosine kinases trkA, trkB, or trkC (Klein et al., 1989, 1991, 1992; Kaplan et al., 1991; Lamballe et al., 1991). Thus, two distinct families of neurotrophic factors, the neuropoietic cytokines and the neurotrophins, by signaling through different receptors regulate neurite outgrowth and regeneration of adult sensory neurons (Gölz et al., 2006; Melemedjian et al., 2010).

We have addressed crosstalk between neuropoietic cytokine and neurotrophin signaling in a mouse mutant with a conditional deletion of $g p 130$ specifically in sensory neurons. Deletion of gp130 in these neurons significantly impaired functional recovery after nerve injury in vivo. The neurite outgrowth of cultured gp130-deficient sensory neurons was strongly reduced in the absence of exogenously added factors, as was the response to neuropoietic cytokines and neurotrophins. We found that the JAK/ STAT3 pathway is a key mediator of both cytokine and neurotrophin signaling in neurite regeneration.

\section{Materials and Methods}

Ethics statement. All experiments were performed with permission under National Austrian Law (BMWF-66.011/0051-II/10b2008; BMWF66.011/0113-II/3b/2010; GZ 66.011/85-C/GT/2007) and according to intensity on the basis of the up-down method (Dixon, 1980; Chaplan et al., 1994), where an $11.4 \mathrm{mN}$ stimulus was applied first. Heat sensitivity was assessed using the Hargreaves test (Hargreaves et al., 1988): paw withdrawal latency in response to an increasing heat stimulus (IR intensity $=51$ ) was determined with an automated algesiometer (Ugo Basile). Motor capabilities were tested by rotarod assay (Acceler Rota-Rod 7650, Ugo Basile). Mice were trained for two sessions before testing on an accelerating (4-40 rpm) rotarod. A $600 \mathrm{~s}$ cutoff time was used. Latencies to fall before $(\mathrm{BL})$ and after surgery $(\mathrm{PL})$ were showed as percentage changes calculated as follows: $[\mathrm{PL} /[(\mathrm{BL} 1+\mathrm{BL} 2) / 2]] \times 100$.

Immunohistochemistry on frozen sections. Glabrous hindpaw skin was dissected and postfixed in 4\% paraformaldehyde (PFA) in PBS for $1 \mathrm{~h}$, cryoprotected in $25 \%$ sucrose in PBS at $4^{\circ} \mathrm{C}$ for at least $24 \mathrm{~h}$, embedded, and frozen in optical cutting medium (Richard-Allan Scientific). Cryostat sections (Lycra CM 1950) of $20 \mu \mathrm{m}$ were mounted on poly-lysinecoated slides (Thermo Scientific) and blocked in 10\% normal goat serum in PBS containing $0.3 \%$ Triton X-100 for $1 \mathrm{~h}$, incubated with primary antibodies $(\alpha$-TuJ $1 ; \alpha$-NF-H) at room temperature for $12 \mathrm{~h}$, washed, and incubated at room temperature with appropriate secondary antibodies for $90 \mathrm{~min}$. After washing sections were transferred to a Leica SP5 confocal microscope and visualized with $63 \times$, NA 1.4 glycerol-immersion objective. Analysis of immunostaining was performed blinded to genotype. Images were processed using EMBL ImageJ (v1.45 h, NIH) with global adjustments in brightness and contrast. Quantification of epidermal sensory innervation density was performed as described previously (Lindfors et al., 2006). In brief, labeled nerve fibers in the epidermis of at least 10 randomly chosen confocal micrographs ( $20 \mu \mathrm{m}$ stacks) of four animals per genotype were counted and the fiber density (no. of fibers/ $1000 \mu \mathrm{m}^{2}$ ) was calculated.

Culture of primary sensory neurons. Lumbar and thoracic DRG were dissected from adult mice as previously described (Obreja et al., 2002a; Agarwal et al., 2007). Ganglia were cleaned from the connective tissue 
A
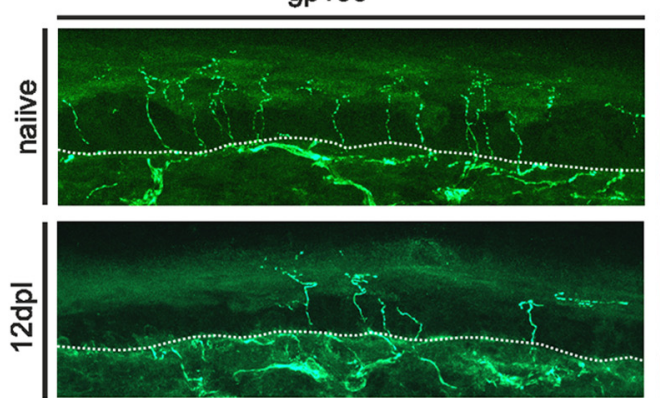

gp130 fl/fl
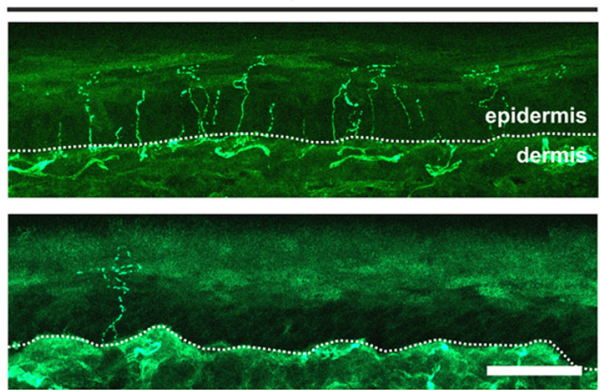

B

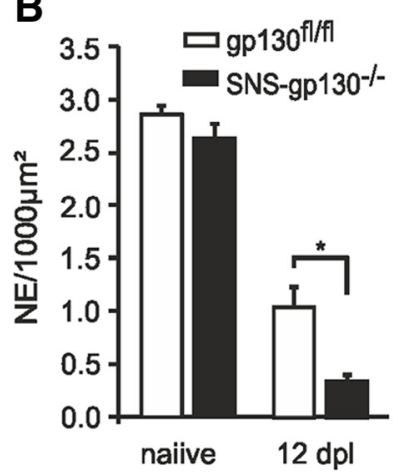

C

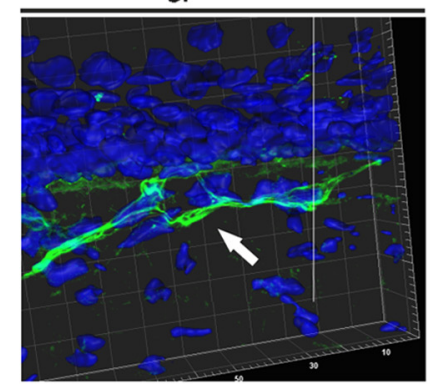

SNS-gp $130^{-/-}$

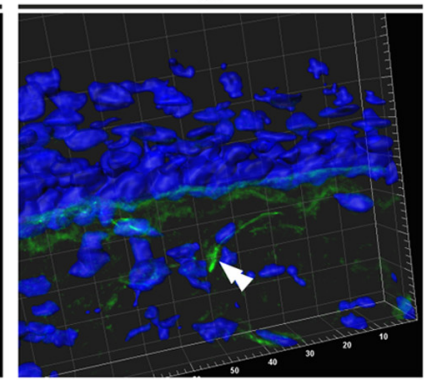

$\mathbf{D}_{\text {TuJ }}$

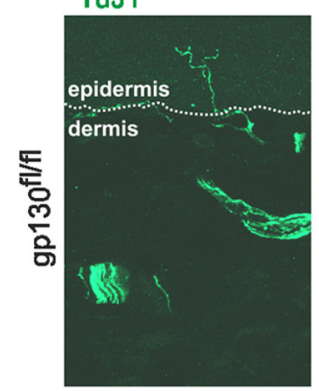

$\alpha-N F$

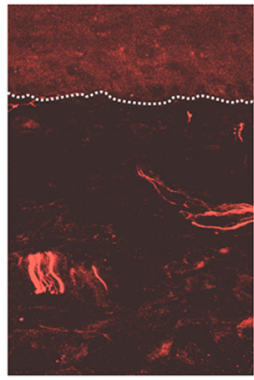

merge

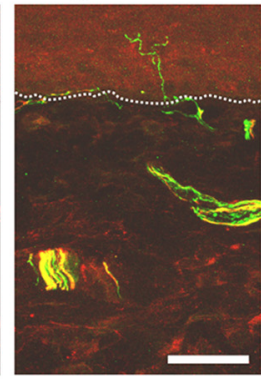

Figure 2. Reduced density of TuJ $-1^{+}$nerve endings in the epidermis in SNS-gp $130^{-1-}$ mice after lesion. $A$, Representative cross sections of hindpaw glabrous skin of naive and $12 \mathrm{dpl} g p 130^{f / f f l}$ and SNS-gp $130^{-1-}$ mice stained with the pan neuronal marker TuJ-1. The dotted line indicates the border between dermis and epidermis. Scale bar, $40 \mu \mathrm{m}$. $\boldsymbol{B}$, Quantification of the total number of TuJ-1 ${ }^{+}$fibers (NE) per $1000 \mu \mathrm{m}^{2}$ of epidermal area shows a significant decrease in density in SNS-gp 130 ${ }^{-1-}$ mice after lesion compared with control animals $\left({ }^{*} p<0.05 ; n=4\right.$ for each group). Data are presented as mean \pm SEM and analyzed by Mann-Whitney U test. C, 3D reconstruction of the deeper layer of the dermis shows fewer nerve bundles in SNS-gp $130^{-1-}$ dermis compared with controls. D, No NF-H ${ }^{+}$proprioceptive fibers were detectable in the epidermis of $g p 130^{f / f t}$ animals at $12 \mathrm{dpl}$. Scale bar, $40 \mu \mathrm{m}$.

and incubated in Liberase Blendzyme 1 ( $9 \mathrm{mg} / 100 \mathrm{ml}$ DMEM, Roche) for $60 \mathrm{~min}$. After washing with PBS, $1 \times$ trypsin-EDTA (Invitrogen) was added for $15 \mathrm{~min}$. TNB medium (Biochrom) containing L-glutamin (Invitrogen), penicillin G sodium, streptomycin sulfate (Invitrogen), and Protein-Lipid-Komplex (Biochrom) was used for washing. After mechanical dissociation with a fire-polished Pasteur pipette, the resulting cell suspension was centrifuged at $500 \mathrm{rpm}$ through a $3.5 \%$ BSA gradient (Sigma-Aldrich) for $10 \mathrm{~min}$. The pellet was resuspended in TNB medium and centrifuged for $5 \mathrm{~min}$ at $760 \mathrm{rpm}$. The neurons were plated on coverslips coated with poly-L-lysine (Sigma-Aldrich) and laminin (10 $\mu \mathrm{g} / \mathrm{ml}$, Sigma-Aldrich) or fibronectin (BD Biosciences). Neurons were cultured in TNB medium at $37^{\circ} \mathrm{C}$ in $5 \% \mathrm{CO}_{2}$ for 20 or $48 \mathrm{~h}$. For in vitro inhibitor studies, inhibitor concentrations from $100 \mathrm{nM}$ to $10 \mu \mathrm{M}$ were tested for toxicity with the cell-proliferation reagent WST-1 (Roche; data not shown). During the experiments, neuronal cultures were preincubated with nontoxic concentrations of the inhibitor for $1 \mathrm{~h}$ before overnight growth factor treatment and control cultures were treated with equal volumes of vehicle (DMSO) which did not affect survival or outgrowth.

Live labeling of neuron cultures. After 20 or $48 \mathrm{~h}$, neurons were livelabeled with $\alpha$-gp 130 antibody diluted in cold TNB medium for $30 \mathrm{~min}$ on ice. After washing, neurons were incubated with the secondary antibody diluted in cold TNB medium for $30 \mathrm{~min}$ and washed with PBS. Cells were fixed either with 4\% PFA for $20 \mathrm{~min}$ at room temperature (RT) or with methanol at $-20^{\circ} \mathrm{C}$ for $2 \mathrm{~min}$. After permeabilization with $0.01 \%$ TX-100 (Pierce) unspecific binding was blocked for 30 min with 10\% normal goat serum (Sigma-Aldrich) in PBS. Cells were incubated with the first antibody for $1 \mathrm{~h}$, washed three times for $10 \mathrm{~min}$ with PBS and incubated with the appropriate secondary antibody for $30 \mathrm{~min}$, counterstained with 4', 6-diamidino-2-phenylindole (1:10,000; Sigma-Aldrich) and embedded in Mowiol (Calbiochem). As primary antibodies, $\alpha$-gp130 (1:50; Neuromics), $\alpha$ - $\beta$-III-tubulin clone TuJ-1 (1:1000; R\&D Systems), and $\alpha$-neurofilament-H ( $\alpha$-NF-H; 1:200; Neuromics) were used. Secondary antibodies used were $\alpha$-goat AlexaFluor 594 (1:1000; Invitrogen), chicken $\alpha$-mouse AlexaFluor 594 or donkey $\alpha$-mouse Alex-
aFluor 488 (1:1000; Invitrogen), and goat $\alpha$-chicken AlexaFluor 568 (1: 10,000; Invitrogen) for fluorescence microcopy.

Outgrowth assay. After $20 \mathrm{~h}$ in culture, SNS-gp130-1- DRG neurons were live labeled to detect the gp130-IR-positive cells which were excluded from the analysis. Neurons were labeled with $\alpha$-TuJ1 antibody to visualize the neurites and digitalized images of randomly chosen areas of the coverslip were taken using an Axio Imager microscope (Carl Zeiss) with $16 \times$, NA 0.5 or $25 \times$, NA 0.8 oil-immersion objective. Images were recorded with a cooled CCD camera (SPOT; Diagnostic Instruments). Approximately 100 cells were scored per condition and in triplicates of experiments as minimum requirement. Only neurons that were clearly separated from neighboring cells were included for quantification. For the analysis of the neurite-bearing cells percentage, neurons with no visible process or with only filopodial formations were counted as negative. Cells showing at least one neurite with total neurite length of at least one cell diameter were counted. Numbers of primary intersections were measured by Sholl analysis, where intersections are defined as the number of neurites directly attached to the soma for a Sholl radius of 20 or 30 $\mu \mathrm{m}$. Quantification was performed using MetaMorph image analysis (Meta Imaging Series 7.1, v7.1.6.0, Molecular Devices) or ImageJ software and NeuronJ plugin (http://www.imagescience.org/meijering/software/ neuronj/; Meijering et al., 2004).

RNA isolation and quantitative real-time PCR. DRG from adult mice were snap-frozen in liquid nitrogen for RT-PCR and stored at $-80^{\circ} \mathrm{C}$ until required. Total RNA was isolated $24 \mathrm{~h}$ after start of the culture using RNeasy Micro kit (Qiagen) according to the manufacturer's instructions. Reverse transcription of $1 \mu \mathrm{g}$ RNA to cDNA was performed using the GeneAmp RNA PCR Kit (Applied Biosystems) with random hexamer primers. RNA and cDNA concentrations were measured photometrically. Each cDNA sample was analyzed for expression of neurotrophin receptors by quantitative real-time PCR using the TaqMan $5^{\prime}$ nuclease assays Mm01219406_m1 (for trkA), Mm00446296_ml (for p75 ${ }^{\mathrm{NTR}}$ ), and Mm01352363_m1 (for succinate dehydrogenase subunit A, Sdha; all from Applied Biosystems). Reactions were performed in a MicroAmp Fast Optical 96-Well Reaction Plate (Applied Biosystems) using the 7500 
A
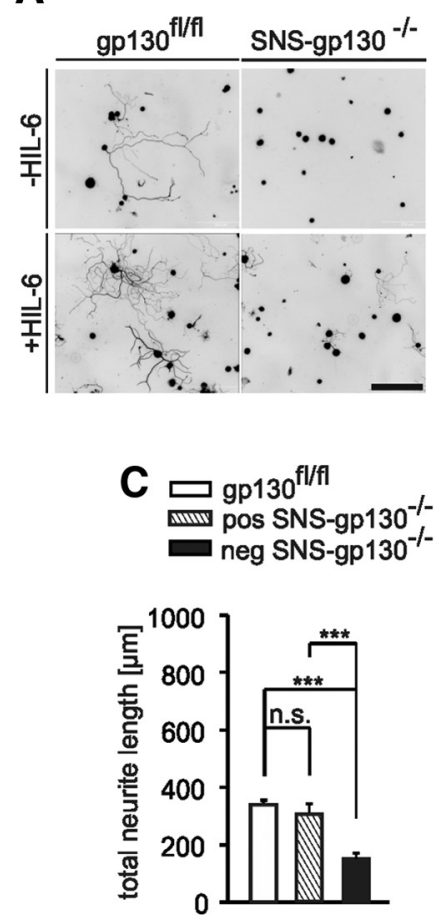

E

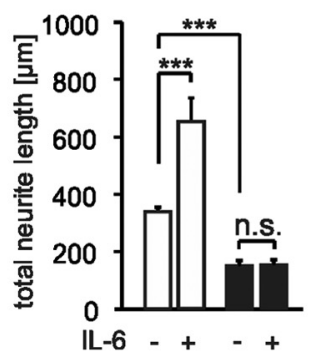

$\mathbf{F}$
B
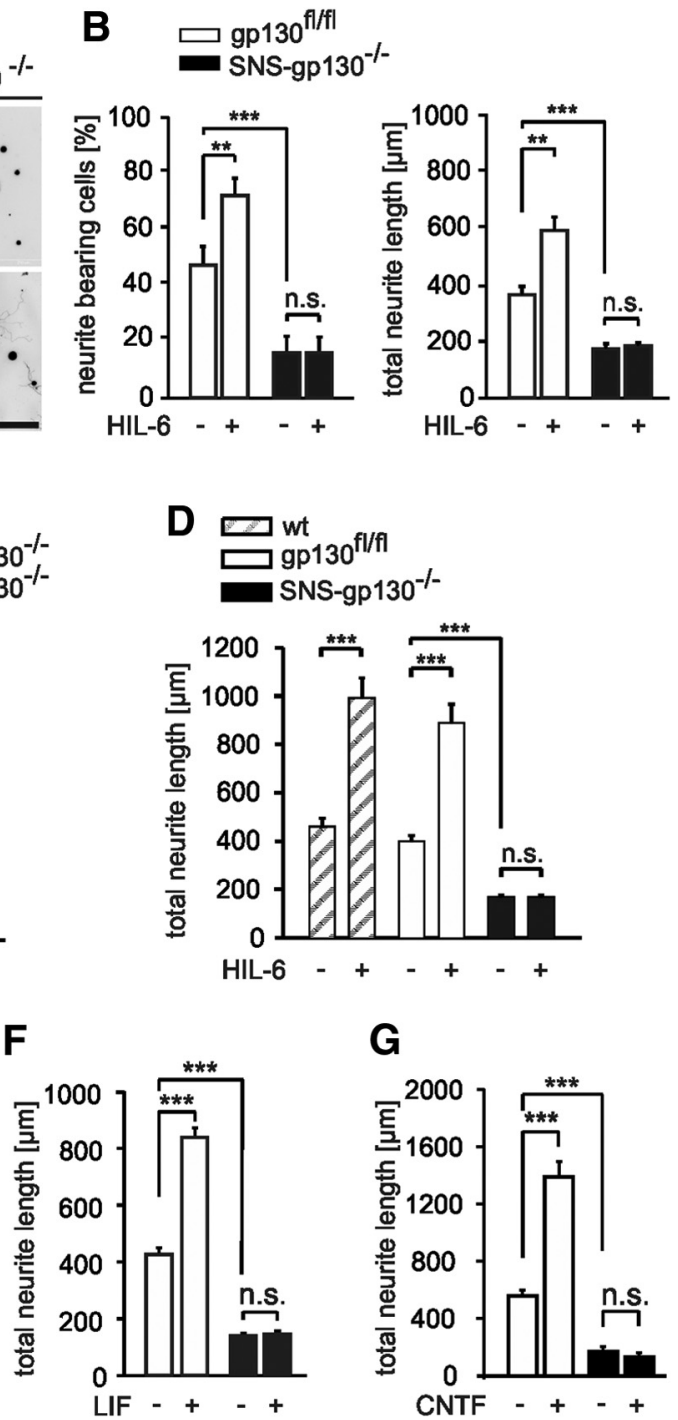

G

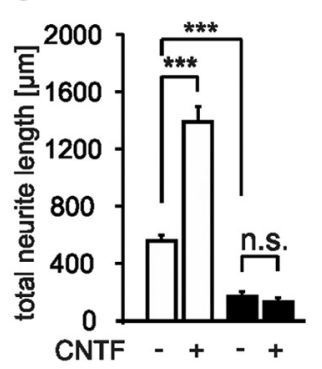

Figure 3. Reduced neurite outgrowth in sensory neurons lacking gp130 in vitro. $\boldsymbol{A}$, Representative examples of DRG neuron cultures from $g p 130^{f / f l}$ and SNS-gp $130^{-1-}$ mice. Scale bar, $210 \mu \mathrm{m}$. Neurons were cultivated with or without HIL-6 (5 ng/ml) for $20 \mathrm{~h}$ and stained with Tuj-1. $\boldsymbol{B}$, The percentage of neurite-bearing cells in control cultures was significantly reduced in nontreated and treated SNS-gp $130^{-I-}$ cultures compared with $g p 130^{f / / f l}$ cultures $\left({ }^{* * *} p<0.001 ; \chi^{2}\right.$ test). Likewise, the total neurite length was significantly shorter in untreated as well as HIL-6 treated SNS-gp $130^{-1-}$ neurons ( $n=75$ nontreated, $n=89$ treated) vs gp130 ${ }^{f l / f l}\left({ }^{* *} p<0.01\right.$; Mann-Whitney $U$ test with Holm correction, $n=122$ nontreated, $n=109$ treated). C, Neurite length of gp130-IR-positive neurons in SNS-gp130 $0^{-1-}$ cultures, $\left(n=47\right.$ pos; $n=47$ neg) was similar to values of control gp $130^{f / f l}$ cells (Mann-Whitney $U$ test with Bonferroni correction, $n=79$ ). $D$, Long-term cultures for $48 \mathrm{~h}$ revealed that the differences between control and SNS-gp $130^{-1-}$ DRG neuronal cultures persisted for at least $2 \mathrm{~d}$ with and without HIL- 6 treatment (for wt, $n=55$ nontreated, $n=63$ treated; for $g p 130^{f / f l}, n=77$ nontreated, $n=40$ treated; for SNS-gp130 ${ }^{-1-}, n=75$ nontreated, $n=69$ treated). $\boldsymbol{E}$, Upon treatment with IL-6 $(5 \mathrm{ng} / \mathrm{ml})$ an increase in neurite length was obtained for $g p 130^{f l / f l}$ neurons $(n=79$ nontreated, $n=87$ treated), whereas SNS-gp $130^{-1-}$ neurons did not respond ( $n=47$ nontreated, $n=51$ treated). $F$, LIF (20 $\mathrm{ng} / \mathrm{ml}$ ) induced an increase of the average length in $g p 130^{f / f l}$ neurons ( $n=73$ nontreated, $n=67$ treated), whereas gp130deficient neurons were not affected ( $n=78$ nontreated, $n=69$ treated). G, Likewise, CNTF ( $20 \mathrm{ng} / \mathrm{ml})$, stimulated outgrowth in gp $130^{f / / f l}$ neurons but had no effect on SNS-gp130 ${ }^{-/-}$neurons $\left(n=121 \mathrm{gp} 130^{f / / f l}\right.$ nontreated, $n=105 \mathrm{gp} 130^{f / / f l}$ treated; $n=$ 11 SNS-gp $130^{-1-}$ nontreated, $n=5$ SNS-gp $130^{-/-}$treated). Data are presented as mean \pm SEM and analyzed by MannWhitney $U$ test with Holm correction, ${ }^{* * *} p<0.001$.

Fast Real-Time PCR System (Applied Biosystems). Samples were run in triplicate using $50 \mathrm{ng}$ of total RNA equivalents (cDNA) and positive and negative controls were included in all the experiments. Threshold cycle $\left(\mathrm{C}_{\mathrm{T}}\right)$ values were recorded as a measure of initial template concentration. Relative fold-changes in RNA levels were calculated by the $\Delta \Delta \mathrm{C}_{\mathrm{T}}$ method using Sdha as a reference standard gene. The fold-change expression, relative to a calibrator sample, was calculated by $2^{-\Delta \Delta \mathrm{CT}}$.

Western blotting. Sensory neurons cultured for $24 \mathrm{~h}$ were growth factor-deprived for $2 \mathrm{~h}$ in extracellular solution (ECS) before stimulation with $5 \mathrm{ng} / \mathrm{ml}$ IL- 6 or $20 \mathrm{ng} / \mathrm{ml} \mathrm{CNTF} \mathrm{for} 10 \mathrm{~min}$ in ECS for the experiments depicted as shown in Figure $5 A$. For the experiments shown in Figures $4 B$ and $6 A$, cell seconds were treated with $100 \mathrm{ng} / \mathrm{ml} \mathrm{NGF}$ for $2 \mathrm{~h}$ or $30 \mathrm{~min}$, respectively. Nontreated cultures were used as controls. Neurons were harvested in freshly prepared ice-cold RIPA-buffer (50 mM Tris$\mathrm{HCl}, 150 \mathrm{~mm} \mathrm{NaCl}, 50 \mathrm{~mm} \mathrm{NaF}, 5$ mm EDTA, $0.5 \%$ deoxycholic acid, $0.1 \%$ SDS, $1 \%$ Nonidet P-40, all Sigma-Aldrich) enriched with 1:10 phosphatase inhibitor complex (Sigma-Aldrich) and 1:1000 phosphatase inhibitor sodium-orthovanadate (Sigma-Aldrich). SDS-PAGE was performed under standard denaturing conditions and lysates were processed as described previously (Andratsch et al., 2009). Protein content was measured with BCA Protein Assay kit (Thermo Scientific) according to the protocol. Equal amounts of protein were loaded. For immunodetection, membranes were incubated with the desired antibodies diluted according to the instructions of the manufactures. Visualization of blots was performed with enhanced chemiluminescence by using the SuperSignal West Pico Chemiluminescent Substrate (Thermo Scientific). Membranes were scanned with LAS4000 luminescent imager (GE Healthcare). Quantification was performed using ImageJ software and relative values for phosphorylated proteins are represented as units after normalization to the nonphosphorylated form. $\alpha$-gp130 (1:1000; Cell Signaling Technology), $\alpha$-phospho-STAT3 (Tyr705) XP (1:2000; Cell Signaling Technology), $\alpha$-STAT3 (1:1000; Cell Signaling Technology), $\alpha$-phospho-ERK1/2 (Thr202/Tyr204) (1: 1000; Cell Signaling Technology), and $\alpha$-ERK1/2 (1:1000; Cell Signaling Technology) were used as primary antibodies, and $\alpha$-rabbit IgG (1:5000; Sigma-Aldrich) secondary antibody for detection.

Compounds and inhibitors. Cytokines or factors used: $5 \mathrm{ng} / \mathrm{ml} \mathrm{IL-6} \mathrm{(Sigma-Aldrich),} 5$ ng/ml HIL-6 (Fischer et al., 1997; Schäfer et al., 1999), $10 \mathrm{ng} / \mathrm{ml}$ LIF (Neuromics), $20 \mathrm{ng} / \mathrm{ml}$ CNTF (Sigma-Aldrich), $100 \mathrm{ng} / \mathrm{ml}$ mNGF $2.5 \mathrm{~S}$ (grade II, Alomone Labs), and $100 \mathrm{ng} / \mathrm{ml}$ leptin (Sigma-Aldrich). Inhibitors: $1.5 \mu \mathrm{M}$ STATTIC (Calbiochem) and $1 \mu \mathrm{M}$ JAKI (Calbiochem).

Statistics. For statistical analysis the SigmaStat 3 software was used and data are presented as mean \pm SEM. Statistical tests were used differently: two-way repeated-measures (RM) ANOVA or one-way ANOVA followed by Tukey post hoc test or Kruskal-Wallis with Mann-Whitney $U$ or Student's $t$ post hoc test with Holm/Bonferroni correction for multiple comparisons between groups; Mann-Whitney $U$ test for intraindividual comparisons. Data were analyzed by $\chi^{2}$ test for comparison of relative group sizes. Differences were considered statistically significant at $p<0.05$.

\section{Results}

Recovery in SNS-gp130 ${ }^{-/-}$mice is delayed after sciatic nerve injury in vivo

The involvement of gp130 signaling in peripheral neuronal regeneration was studied in the sciatic nerve crush injury in vivo 
A

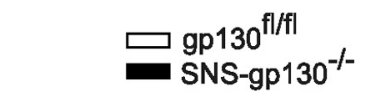

B
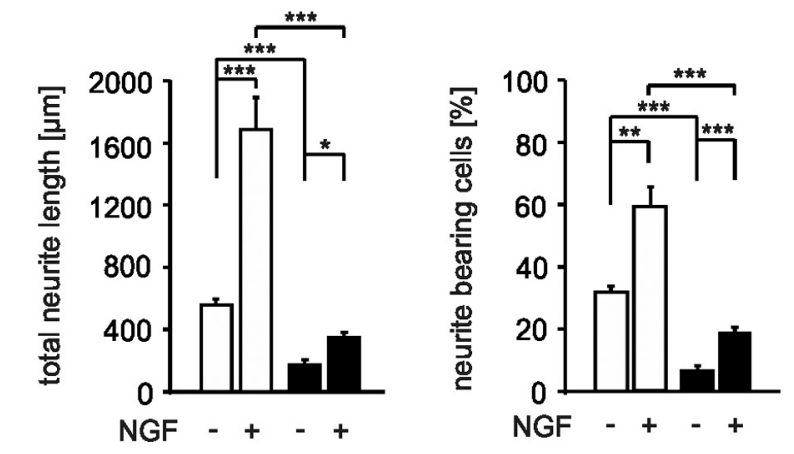

C
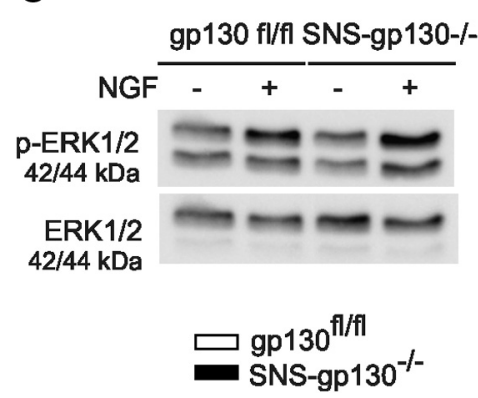

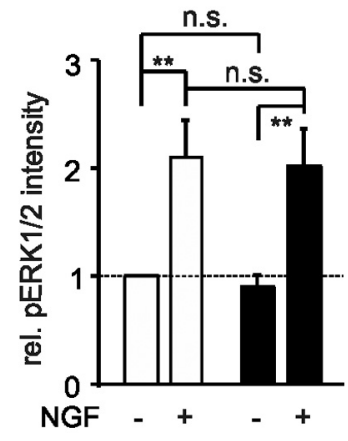

Figure 4. Reduced in vitro outgrowth of neurons lacking gp130 in response to NGF. A, NGF $(100 \mathrm{ng} / \mathrm{ml})$ increased the total neurite length of $g p 130^{f / f l}$ neurons $(n=99$ nontreated, $n=$ 105 treated) but only led to a minimal increase of neurite outgrowth in SNS-gp $130^{-/-}$neurons ( $n=11$ nontreated, $n=51$ treated). $\boldsymbol{B}$, The histogram on the right shows the percentage of neurite-bearing cells, which was significantly smaller in knock-out cultures compared with controls upon treatment $\left(n=615 \mathrm{gp} 130^{\mathrm{fl} / \mathrm{fl}}\right.$ nontreated, $n=391 \mathrm{gp} 130^{\mathrm{f} / / \mathrm{fl}}$ treated; $n=516$ SNS-gp $130^{-1-}$ nontreated, $n=515$ SNS-gp $130^{-/-}$treated). C, Representative example of Western blot and quantification of phospho-ERK1/2 (pERK1/2) versus total ERK1/2 obtained from treated and nontreated DRG cultures. Treatment with NGF $(100 \mathrm{ng} / \mathrm{ml})$ for $2 \mathrm{~h}$ led to similar increase of pERK1/2 in both DRG cultures from gp $130^{f / f / l}$ and SNS-gp $130^{-1-}$ mice $(n=4$; ${ }^{* *} p<0.01$, one-way ANOVA, Tukey post hoc test). No difference was observed in total ERK1/2 between the two strains and total ERK1/2 was used as a loading control. Values for pERK1/2 were related to ERK1/2 nonphosphorylated and represented as relative intensity. Data are presented as mean \pm SEM and analyzed by Mann-Whitney $U$ test with Holm correction or $\chi^{2}$ test; ${ }^{*} p<0.05$, ${ }^{* *} p<0.01,{ }^{* * *} p<0.001$.

model using the SNS-gp130-1- mouse strain. In this strain the gp130 subunit is selectively deleted in nociceptive sensory neurons expressing the SNS sodium channel NaV1.8 (Andratsch et al., 2009). Functional nerve recovery was monitored for $25 \mathrm{dpl}$ by determining sensory thresholds and motor capabilities in adult mice expressing gp130 from wild-type (wt), or floxed alleles $\left(g p 130^{f l f l}\right)$. Both strains were compared with SNS-gp130 mice. Mechanical sensory thresholds were significantly elevated by approximately fourfold in all mouse strains within the first 4 $\mathrm{dpl}\left(\right.$ day -1 vs day $1, p=0.000012$ for $g p 130^{f l / f l}, p=0.000012$ for wt, $p=0.000012$ for SNS- $g p 130^{-/-} ; g p 130^{f l / f l}$ vs wt, $p=0.139$; two-way RM ANOVA, Tukey post-test; $n=8)$. In gp130 expressing mice (wt and $g p 130^{f l f l}$ ), mechanical thresholds started to recover from day 8 but remained elevated in SNS-gp $130^{-1-}$ mice (Fig. $1 A ; 23.95 \pm 1.60 \mathrm{mN}$ for $g p 130^{f l f l}$ vs $54.58 \pm 0.0 \mathrm{mN}$ for SNS-gp130 ${ }^{-1-} ; p<0.001$, two-way RM ANOVA, Tukey posttest; $n=8$ ). Heat sensitivity was likewise decreased after nerve injury in all three strains and returned to the baseline at day 4 in wt and $g p 130^{f l f l}$ animals (Fig. $1 B$; day -1 vs day $1, p=0.00089$ for $g p 130^{f l f l}, p=0.069$ for wt, $p=0.000013$ for SNS- $g p 130^{-\prime-}$; $g p 130^{f l f l}$ vs wt, $p=0.487$; two-way RM ANOVA, Tukey post-test; $n=8)$. In SNS-gp130 ${ }^{-l-}$ mice recovery was severely delayed and reached baseline only at day 22 (Fig. $1 B ; 8.56 \pm 0.50 \mathrm{~s}$ for $g p 130^{f l / f l}$ vs $13.28 \pm 0.90 \mathrm{~s}$ for SNS- $g p 130^{-1-} ; p=0.001$, two-way RM ANOVA, Tukey post-test; $n=8$ ). Because expression of Cre recombinase and respective deletion of gp130 was restricted in our experiments to the nociceptive Nav1.8-positive sensory neuronal subpopulation without affecting myelinated sensory neurons, we expected no difference in motor recovery between mouse strains. Indeed, there was no difference in the recovery of motor function between $g p 130^{f l f l}$ and $S N S-g p 130^{-1-}$ mice as determined by the rotarod test (Fig. $1 C$; two-way RM ANOVA, n.s., $n=8$ ). Therefore, the observed delay in functional recovery of peripheral neurons after nerve injury in vivo is consistent with a selective dysfunction of the neurons in which $g p 130$ was genetically ablated, whereas recovery of motor functions remains unaltered after injury. These results suggest an important cell autonomous role for neuronal gp130 signaling during peripheral nerve regeneration.

\section{Cutaneous reinnervation in $S N S-g p 130^{-1-}$ mice is retarded after injury}

SNS-gp130-l- mice do not show any developmental deficits or overall altered composition of sensory neuron populations in the DRG (Andratsch et al., 2009). In line with these data, the number of Tuj- ${ }^{+}$free nerve endings per square micrometer was similar in untreated $g p 130^{f l f l}$ and $S N S-g p 130^{-1-}$ mice (Fig. $2 A, B ; 2.85 \pm$ $0.09 \mathrm{NE}$ for $g p 130^{f l f l}$ vs $2.63 \pm 0.14 \mathrm{NE}$ for SNS-gp130 ${ }^{-l-}$; MannWhitney $U$ test, $n=4$ animals per strain, $n=512 \mathrm{NE}$ counted for $g p 130^{f l f l} ; n=462 \mathrm{NE}$ for SNS-gp130 $\left.n 0^{-/-}\right)$. Therefore, skin of SNS- $g p 130^{-1-}$ mice is normally innervated before injury. To assess cutaneous reinnervation after injury in vivo, the number of free nerve endings in the skin was analyzed in the plantar innervation territory of the sciatic nerve. Only exceptionally were Tuj1 -positive sensory neuronal endings detected in both mouse strains $8 \mathrm{dpl}$ (data not shown). At $12 \mathrm{~d}$ after crush-lesion, the first Tuj-1-immunopositive axonal profiles reinnervating sweat glands and skin of the injured hindpaws were visible. Quantitative analysis revealed a significantly lower number of free nerve endings in the epidermis of SNS-gp130 ${ }^{-1-}$ mice versus controls $\left(0.34 \pm 0.06 \mathrm{NE}\right.$ for $S N S$ - $g p 130^{-/-}$vs $1.04 \pm 0.19 \mathrm{NE}$ for $g p 130^{f l / f l}$; $p=0.029$, Mann-Whitney $U$ test, $n=4$ animals per strain, $n=$ $178 \mathrm{NE}$ counted for $g p 130^{f l / f l} ; n=59 \mathrm{NE}$ for $S N S-g p 130^{-\prime-}$; Fig. $2 A, B)$. These nerve endings in $g p 130^{f l f l}$ mice were negative for $\mathrm{NF}-\mathrm{H}$ and thus very likely represent regenerating nociceptive fibers (Fig. 2D; Aoki et al., 2004; Zylka et al., 2005). Differences in neuronal fiber bundles in animals lacking gp130 in nociceptors were also detected in deeper layers of the dermis. 3D reconstructions show that nerve bundles were already regenerating at $12 \mathrm{dpl}$ at high-frequency at the level of the dermis in $g p 130^{f l f l}$ mice, whereas none or fewer nerve bundles were found in SNS$g p 130^{-1-}$ dermis (Fig. 2C). These morphological changes suggest that the delay in functional recovery detected after injury in SNS$g p 130^{-/-}$mice in our behavioral test is caused by impairment in axon regeneration and target tissue reinnervation.

\section{Neurite outgrowth is inhibited in cultures of adult SNS-gp130 ${ }^{-/-}$DRG neurons}

The above data suggested that gp130 regulates the regenerative post-lesion response of injured neurons in vivo. As an in vitro model of neuronal injury, we analyzed the effect of $g p 130$ ablation on the intrinsic growth capacity of adult primary DRG neuronal cultures. To this end DRG neurons from SNS$g p 130^{-1-}$ and $g p 130^{f l / f l}$ mice were cultured for $20 \mathrm{~h}$ in absence of 


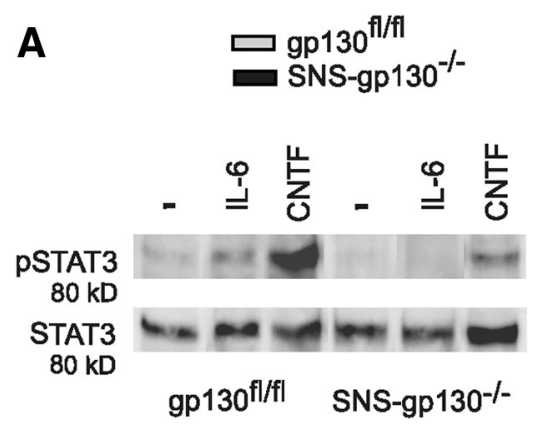

B
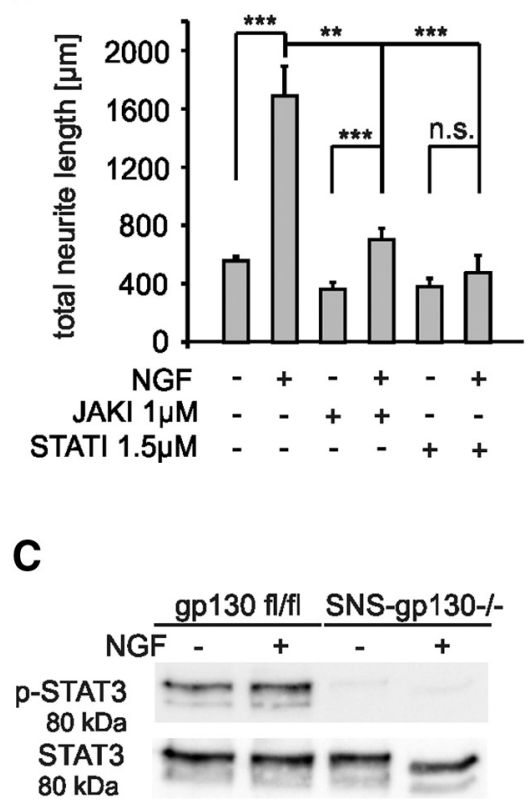
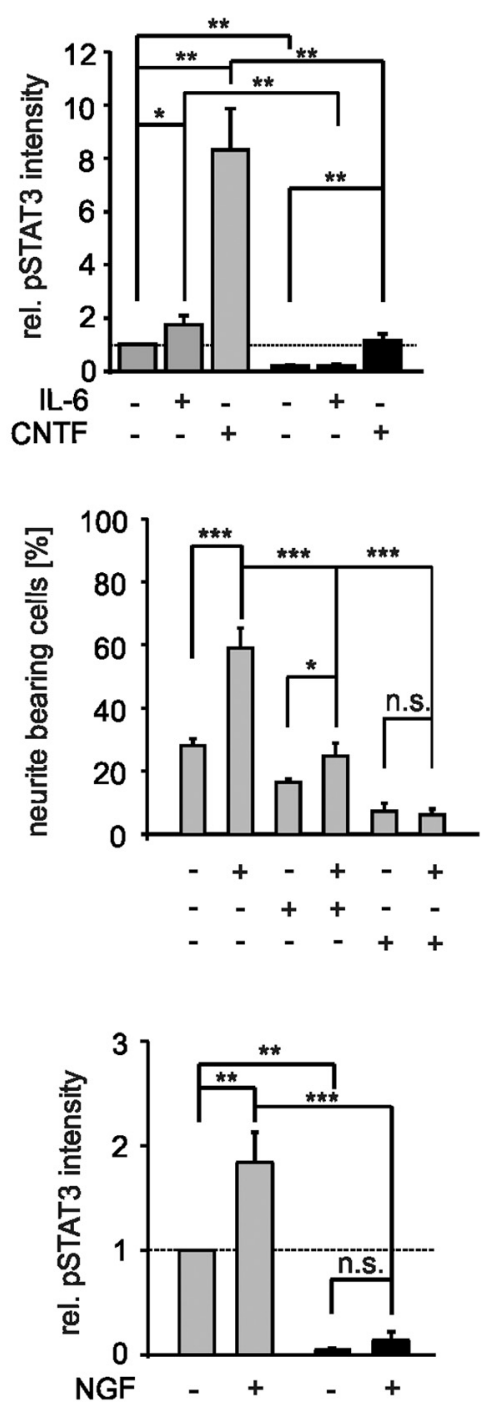

Figure 5. Reduced phospho-STAT3 in gp130-deficient cultures and inhibitor effect of Stattic and JAKI. $\boldsymbol{A}$, Representative example of Western blot and quantification of pSTAT3 versus total STAT3 obtained from treated and untreated DRG cultures. Treatment with IL-6 $(5 \mathrm{ng} / \mathrm{ml})$ or CNTF $(20 \mathrm{ng} / \mathrm{ml})$ for 10 min led to increase of pSTAT3 in DRG cultures from $\mathrm{gp} 130^{f / f t}$ mice, whereas SNS-gp $130^{-1-}$ cultures showed no or strongly reduced pSTAT3 at baseline, as well as upon treatment ( $n=4 \mathrm{ctrl} ; n=3 \mathrm{for}+\mathrm{IL} 6$; $n=4$ for + (NTF). Quantification of the Western blot results revealed significant reduction in the basal pSTAT3 in SNS-gp $130^{-\prime-}$ cultures compared with control ( $n=4 ;{ }^{*} p<0.05,{ }^{* *} p<0.01,{ }^{* * *} p<0.001$, Student's $t$ test with Holm correction). Total STAT3 was used as a loading control and no difference was observed in total STAT3 between the two strains. Values for PSTAT3 were related to STAT3 nonphosphorylated and represented as relative intensity. $\boldsymbol{B}$, Treatment of control $g p 130^{f / f t}$ neurons with Stattic or JAK inhibitor in absence of exogenous growth factors or cytokines significantly reduced the percentage of neurite-bearing neurons and the total neurite length (Table 1). Additionally, $1 \mathrm{~h}$ inhibitor pretreatment decreased NGF elongating effect (Table 1); ${ }^{*} p<0.05,{ }^{* *} p<0.01,{ }^{* * *} p<0.001$, Mann-Whitney U test with Holm correction or $\chi^{2}$ test. C, Representative example of Western blot and quantification of pSTAT3 vs total STAT3 obtained from treated and untreated DRG cultures. In quantification analysis pSTAT3 levels were significantly increased upon treatment with NGF (100 ng/ml) for $30 \mathrm{~min}$ in $g p 130^{f / f f l}$ DRG cultures. No significant activation of STAT3 by NGF occurred in cultures from SNS-gp $130^{-1-}$ mice $\left(n=3 ;{ }^{* *} p<0.01\right.$, ${ }^{* * *} p<0.001$, one-way ANOVA, Tukey post hoc test).

exogenous factors on a poly-L-lysine/laminin matrix before analysis. Neuronal cultures prepared with the method described above were enriched of Nav1.8-positive neurons as shown previously (Agarwal et al., 2004; Andratsch et al., 2009). The analysis was restricted to SNS-gp130-/- DRG neurons because gp130positive cells in the cultures were detected by their gp130 immunoreactivity and were excluded from the analysis. A significant reduction in both the proportion of neurite-bearing cells $\left(16.11 \pm 5.86 \%\right.$ for SNS- $g p 130^{-1-}$ neurons vs $47.28 \pm 6.77 \%$ for $g p 130^{f l / f l} ; p=0.000001, \chi^{2}$ test; Fig. $\left.3 A, B\right)$ and the total neurite length was observed for gp130-deficient neurons compared with controls $(173.11 \pm 18.29 \mu \mathrm{m}$ for SNS-gp130 neurons vs $364.34 \pm 29.52 \mu \mathrm{m}$ for $g p 130^{f l}$ $f l ; p=0.000003$, Mann-Whitney $U$ test with Holm correction; Fig. $3 A, B)$. However, Sholl analysis showed no significant difference in the number of primary intersections close to the cell body for a Sholl radius of 20 and $30 \mu \mathrm{m}$ between $g p 130^{f l / f l}$ and SNS- $g p 130^{-1-}$ neurons (data not shown; $p=0.260$ for $20 \mu \mathrm{m}, p=0.866$ for $30 \mu \mathrm{m})$.

Because gp130 was only ablated from the SNS expressing population, we next analyzed gp130 expressing and nonexpressing neurons separately on the same culture dish. Although neurons lacking gp130 exhibited impaired neurite growth, neurons expressing immunoreactivity for gp130 in SNS-gp130-/- cultures showed normal average neurite length not different from wt or $g p 130^{f l f l}$ mice $(p=0.0867$, Mann-Whitney $U$ test with Bonferroni correction; Fig. 3C). Furthermore, cultures from SNS-Cre animals presented a similar growth capacity comparable to $g p 130^{f l f l}$ animals (data not shown).

The decrease in total neurite length was also detected in SNS-gp130 1 - cultures at $48 \mathrm{~h}$ (Fig. 3D) or when neurons were cultured on fibronectin matrix instead of laminin (data not shown).

Next, we tested the effect of gp130 ligands on neurite outgrowth. In cultures from control mice hyper-IL-6 (HIL-6; Fischer et al., 1997; Schäfer et al., 1999) treatment increased neurite length compared with untreated cultures. By contrast, treatment of SNS-gp130 neurons had no effect on neurite length. The difference after ligand treatment between SNS-gp130 $130^{-1-}$ neurons and control neurons was highly significant $\left(183.41 \pm 13.17 \mu \mathrm{m}\right.$ for SNS-gp130 ${ }^{-1-}$ vs $591.44 \pm 47.33 \mu \mathrm{m}$ for $g p 130^{f l / f l} ; p=$ 0.000004 , Mann-Whitney $U$ test with Holm correction; Fig. 3B). Likewise, the percentage of neurite-bearing cells in $g p 130^{f l f l}$ cultures was increased upon ligand treatment, whereas the percentage of SNS-gp130 $1-$ neurons growing neurites remained unchanged $(16.31 \pm 5.59 \%$ for SNS- $g p 130^{-l-}$ vs $71.92 \pm 6.25 \%$ for $g p 130^{f l f l} ; p=0.000001, \chi^{2}$ test; Fig. $3 A, B)$. Also, other gp130 agonists including IL-6, LIF, and CNTF effectively increased neurite outgrowth in control but not in SNS-gp130-1- neurons (Fig. 3E-G).

The floxed gp130 allele targets exon 15 of the locus, which encodes the transmembrane domain, potentially leading to the translation of soluble ligand binding domains from the targeted locus (Betz et al., 1998). Such proteins were not detectable by Western blotting in our cultures obtained from SNS-gp130 animals compared with control (data not shown). Therefore, we 
Table 1. Total neurite length and percentages of neurite-bearing cells (n.b.c.s) in $g p 130^{f l / f I}$ cultures in presence of Stattic or JAK inhibitors and before or after NGF

\begin{tabular}{|c|c|c|c|c|c|c|}
\hline & $\begin{array}{l}\text { Neurite length } \\
(\mu \mathrm{m})\end{array}$ & $p$ & $n$ & $\begin{array}{l}\text { n.b.c. } \\
\%\end{array}$ & $p$ & $n$ \\
\hline Ctrl & $555.27 \pm 30.27$ & & 154 & $28.18 \pm 2.11$ & & 891 \\
\hline NGF & $1686.73 \pm 204.53$ & $0.000007^{a}$ & 105 & $59.05 \pm 6.39$ & $<0.000001^{a}$ & 391 \\
\hline $1 \mu \mathrm{M}$ JAKI & $361.69 \pm 47.59$ & $0.004644^{a}$ & 42 & $16.53 \pm 1.02$ & $0.0000056^{a}$ & 286 \\
\hline $\mathrm{NGF}+1 \mu \mathrm{M}$ JAKI & $702.69 \pm 76.60$ & $\begin{array}{l}0.004797^{b} \\
0.000006^{c}\end{array}$ & 68 & $24.84 \pm 4.13$ & $\begin{array}{r}<0.000001^{b} \\
0.026638^{c}\end{array}$ & 280 \\
\hline $\begin{array}{l}1.5 \mu \mathrm{m} \text { Stattic } \\
\mathrm{NGF}+1.5 \mu \mathrm{M} \text { Stattic }\end{array}$ & $\begin{array}{l}379.31 \pm 56.81 \\
474.88 \pm 119.35\end{array}$ & $\begin{array}{l}0.05505^{a} \\
0.000005^{b} \\
0.968337^{d}\end{array}$ & $\begin{array}{l}24 \\
17\end{array}$ & $\begin{array}{l}7.21 \pm 2.65 \\
6.12 \pm 1.91\end{array}$ & $\begin{array}{r}<0.000001^{a} \\
<0.000001^{b} \\
0.407560^{d}\end{array}$ & $\begin{array}{l}309 \\
296\end{array}$ \\
\hline
\end{tabular}

Mann-Whitney $U$ test with Holm correction or $\chi^{2}$ test.

${ }^{a}$ Comparison versus Ctrl.

${ }^{b}$ Comparison versus NGF.

'Comparison for $1 \mu \mathrm{M}$ JAKI without versus with NGF.

${ }^{d}$ Comparison for $1.5 \mu \mathrm{m}$ Stattic without versus with NGF.

exclude that exogenously added cytokines are scavenged by soluble gp130 domains in our experiments with SNS-gp130 ${ }^{-1-}$ cultures. Rather our results support the idea that gp130 is a determining factor of neurite length and number of cultured adult sensory neurons, both in the presence and absence of exogenously added ligands.

\section{Cultured gp130-deficient neurons are impaired in their response to the neurotrophin NGF}

The neurotrophin nerve growth factor NGF is generally accepted to support adult neuronal regeneration and specifically neurons exposed to NGF in culture elongate their neurites (Terenghi, 1999; Yamashita et al., 1999). To assess the effect of this factor on neurite outgrowth, neurons were cultured for $20 \mathrm{~h}$ with or without NGF (100 ng/ml).

In the presence of NGF total neurite length of $g p 130^{f l f l}$ DRG neurons was significantly increased from $557.23 \pm 38.31 \mu \mathrm{m}$ (nontreated, $n=99$ ) to $1686.73 \pm 204.53 \mu \mathrm{m}$ (treated group, $n=105 ; p=0.000002$, Mann-Whitney $U$ test with Holm correction; Fig. $4 A$ ).

Total neurite length upon addition of NGF to SNS-gp130 DRG was significantly shorter compared with controls (346.06 \pm $34.58 \mu \mathrm{m}$ in treated group, $n=51$ vs $169.13 \pm 36.43 \mu \mathrm{m}$ in nontreated, $n=11 ; p=0.031093$ or vs $1686.73 \pm 204.53 \mu \mathrm{m}$ in gp $130{ }^{\mathrm{fl} / \mathrm{fl}}$ treated group, $n=105 ; p=0.000003$, Mann-Whitney $U$ test with Holm correction; Fig. $4 A$ ). The percentage of neuritebearing cells was increased to $59.05 \pm 6.39 \%$ in $g p 130^{f l f l}$ neuronal cultures, whereas it was significantly lower in SNS-gp $130^{-1-}$ $\left(18.28 \pm 2.03 \%, p<0.000001, \chi^{2}\right.$ test; Fig. $\left.4 B\right)$. Thus, NGF treatment did not fully recover the deficit in neurite outgrowth of SNS-gp130-1- DRG neurons. The reduced NGF outgrowth response of SNS-gp130 ${ }^{-/-}$DRG neurons was not due to changes in NGF receptor expression levels, because mRNA levels for the neurotrophin receptors trkA and p75NTR were similar in DRG neurons from SNS- $g p 130^{-1-}$ and $g p 130^{f l / f l}$ animals $24 \mathrm{~h}$ after plating (data not shown). Phosphorylation levels of the MAP kinases ERK1/2 $2 \mathrm{~h}$ after NGF treatment were elevated to similar levels in both $g p 130^{f l f l}$ and SNS- $g p 130^{-1-}$ treated neuronal cultures $\left(n=4, p=0.01 g p 130^{f l f l}, p=0.006\right.$ SNS-gp130 ${ }^{-l-}$; oneway ANOVA, Tukey post-test; Fig. 4C). This indicates that stimulation of trkA NGF receptors could still normally activate downstream ERK pathway in SNS-gp130-1- DRG cultures despite the difference in outgrowth.

Together, these data demonstrate that in the absence of gp130, the activity of the neurotrophin NGF, which signals through other classes of receptors and do not bind to gp130-containig receptors, is insufficient to support maximal neurite outgrowth in cultures of adult sensory neurons. Therefore, gp130 determines neurite outgrowth of adult DRG neurons in vitro, and in its absence, the growth promoting activities not only of its own cytokine ligands but also of NGF are inhibited or reduced.

\section{Inhibition of STAT3 activity reduces neurite outgrowth}

gp130-dependent cytokines signal through the JAK/STAT and MAPK pathways (Heinrich et al., 2003). Members of the STAT family, in particular STAT3, are activated following peripheral injury (Schwaiger et al., 2000; Qiu et al., 2005). We compared activated phospho-STAT3 (pSTAT3) levels before and after IL-6 or CNTF treatment in DRG cultures from control and SNS$g p 130^{-1-}$ mice. Levels of total STAT3 were similar in all samples and served as a reference to calculate relative intensities for pSTAT3 presented as arbitrary units. In cultures from control mice, relative pSTAT3 intensity was increased two times over control by IL- 6 and eight times by CNTF $(n=4$ control and CNTF, $p=0.0021 ; n=3$ IL-6, $p=0.0411$; Student's $t$ test with Holm correction; Fig. 5A). No increase of pSTAT3 levels occurred after IL- 6 and the CNTF treatment of SNS-gp130 ${ }^{-1-}$ cultures had little effect on STAT3 activation. pSTAT3 levels were significantly lower for all conditions in cultures obtained from SNS- $g p 130^{-1-}$ compared with mice $g p 130^{f l f l}$ mice $(n=4$ control and CNTF, $p=0.0020 ; n=3$ IL-6, $p=0.0049$; Student's $t$ test with Holm correction; Fig. 5A). In particular in SNS-gp130 cultures, the basal pSTAT3 activity in untreated cultures was significantly decreased compared with cultures from $g p 130^{f l f l}$ mice ( $n=4$ control, $p=0.00537$; Student's $t$ test with Holm correction; Fig. $5 A$ ).

To study the function of STAT3 activation during neurite outgrowth of adult sensory neurons, pharmacological inhibitors of STATs or JAKs were used. The Stattic compound selectively inhibits STAT3 and reduces phospho-STAT3 Tyr705 levels, whereas phospho-STAT1 Tyr701 levels remain unchanged (Schust et al., 2006). The used JAK inhibitor (JAKI) blocks the activity of JAK1, -2, and -3 (Thompson et al., 2002; Pedranzini et al., 2006). Stattic or JAKI added at nontoxic doses to wild-type neuron cultures significantly reduced the percentage of neuritebearing cells, as well as total neurite length (Table 1; Fig. 5B). Next, we tested the effect of NGF on neurite outgrowth in the presence of Stattic and JAKI in DRG cultures. The total neurite length of NGF treated wild-type neurons was significantly decreased upon JAK/STAT inhibition (Table 1; Fig. 5B). Likewise, the percentage of neurite-bearing neurons was reduced (Table 1; Fig. 5B). Comparison between untreated and NGF-treated cul- 
A

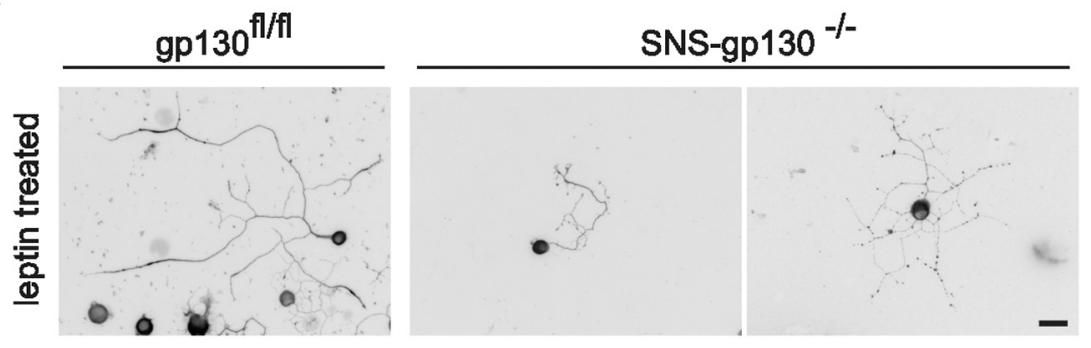

B

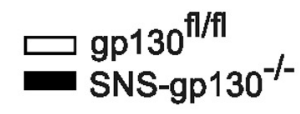

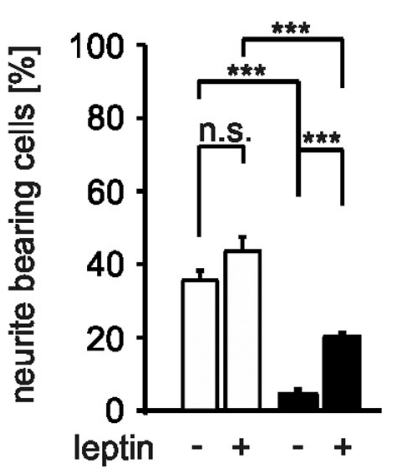

D
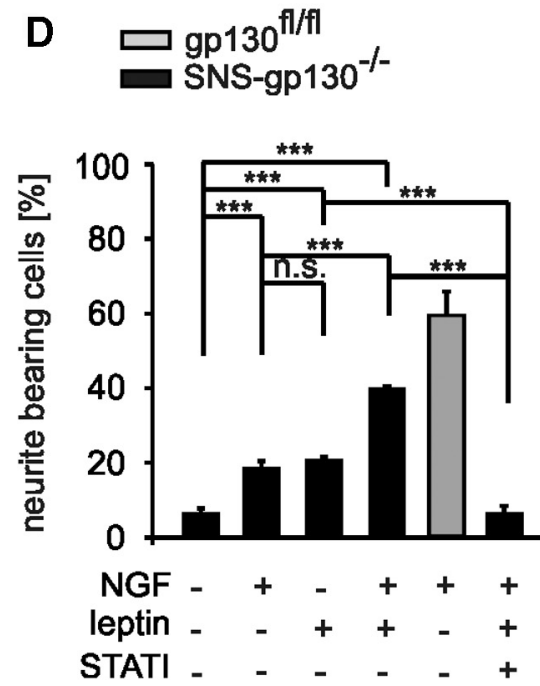

Figure 6. Partial rescue of neurite outgrowth in SNS-gp $130^{-1-}$ cultures through alternative STAT3 activation with leptin. $\boldsymbol{A}$, Representative examples of control and gp130-deficient neurons treated with leptin and stained with Tuj-1. Scale bar, $30 \mu \mathrm{m}$. $\boldsymbol{B}$, Leptin, that activates STAT3 via a gp130-independent pathway, increased the average length of control neurons $\left({ }^{* * *} p<0.001\right.$; Mann-Whitney $U$ test with Holm correction, $n=121$ nontreated, $n=59$ treated). Moreover, leptin partially restored neurite outgrowth in SNS-gp $130^{-/-}$neurons $\left(^{*} p<0.05\right.$; Mann-Whitney $U$ test with Holm correction, $n=11$ nontreated, $n=36$ treated). The number of neurite-bearing cells was increased in leptin treated compared with nontreated SNS-gp $130^{-1-}$ cultures $\left({ }^{* * *} p=0.000001 ; \chi^{2}\right.$ test, for $g p 130^{f l / f l} n=388$ nontreated, $n=$ 166 treated; for SNS-gp $130^{-1-} n=305$ nontreated, $n=184$ treated). C, SNS-gp $130^{-1-}$ cultures were stimulated with the combination of NGF and leptin. This treatment recovered total neurite length to the levels of NGF-treated control neurons ( $p=0.447$; Mann-Whitney $U$ test with Holm correction). This effect was in turn inhibited by Stattic (for SNS-gp130 $-1-n=11$ nontreated, $n=51$ NGF treated, $n=36$ leptin treated, $n=95$ NGF+leptin, $n=19$ $\mathrm{NGF}+$ leptin $+1.5 \mu \mathrm{m}$ Stattic; for gp $130^{\mathrm{fl} / \mathrm{fl}} n=105 \mathrm{NGF}$ treated). $\boldsymbol{D}$, The percentage of neurite-bearing cells was largely recovered by coapplication of NGF and leptin in knock-out cultures and this effect was abolished by the addition of Stattic (for SNS-gp130 ${ }^{-1-} n=516$ nontreated, $n=515$ NGF treated, $n=184$ leptin treated, $n=271$ NGF + leptin, $n=280$ NGF + leptin + $1.5 \mu \mathrm{m}$ Stattic; for $g p 130^{f l / f l} n=391$ NGF treated). Data are presented as mean \pm SEM and analyzed by Mann-Whitney U test with Holm correction or $\chi^{2}$ test; ${ }^{*} p<0.05,{ }^{* *} p<0.01,{ }^{* * *} p<0.001$.

tures showed a significant reduction of the NGF effect in the presence of the inhibitors (Table 1; Fig. 5B). In particular, the reduction by the Stattic compound was not reversed by NGF. Therefore JAK kinase and STAT3, in particular, are suggested to be involved in the intrinsic neurite outgrowth as well as in response to the neurotrophin NGF of wild-type neurons.

Moreover, STAT3 activation in the presence of NGF has been reported for several cell types including sensory neurons (Donnerer et al., 2005; Ng et al., 2006; Zhou and Too, 2011).

We quantified pSTAT3 levels in the absence and presence of NGF for $30 \mathrm{~min}$ in DRG cultures from control and SNS$g p 130^{-1-}$ mice. pSTAT3 levels increased approximately twofold in NGF-treated $g p 130^{f l / f l}$ cultures compared with untreated controls. pSTAT3 levels were hardly detectable in SNS-gp130 ${ }^{-1-}$ cultures and no significant increment occurred in NGF treated SNS- $g p 130^{-1-}$ cultures $(n=3, p=0.008$ $g p 130^{f / f l}, p=0.948$ SNS- $g p 130^{-1-}$; one-way ANOVA, Tukey post-test; Fig. $5 C$ ).

These data suggest that activation of the JAK/STAT pathway is deficient in SNS$g p 130^{-1-}$ neuron cultures and that activation of JAK/STAT is one of the critical pathways for neurite outgrowth of sensory neurons without exogenously added factors and also when neuropoietic cytokines or NGF are added.

\section{Rescue of neurite outgrowth by} activation of STAT3 by leptin To test whether restoration of STAT3 activity was sufficient to stimulate neurite outgrowth and to rescue the deficit in neurite growth of SNS-gp130-1- neurons, DRG cultures from SNS-gp130 $130^{-1-}$ and $g p 130^{f l / f l}$ mice were treated with leptin $(100 \mathrm{ng} / \mathrm{ml})$, which alternatively activates STAT3 via its own leptin receptor independently of gp130. In the absence of other added factors, leptin in cultures from control mice stimulated neurite outgrowth (557.99 $\pm 41.67 \mu \mathrm{m}$ untreated, $n=121$ vs $1240.27 \pm 172.38 \mu \mathrm{m}$ treated, $n=59 ; p=$ 0.000003 , Mann-Whitney $U$ test with Holm correction; Figs. 6A, $B, 3 A$ ) and increased the number of neurite-bearing cells $(35.68 \pm 2.65 \%$ untreated vs $43.48 \pm$ $4.04 \%$ treated; $p=0.11056, \chi^{2}$ test; Fig. $6 B)$. Leptin also partially rescued neurite outgrowth in neurons from SNSgp130 ${ }^{-1-}$ mice $(169.13 \pm 36.43 \mu \mathrm{m}$ untreated, $n=11$ vs $627.63 \pm 145.94 \mu \mathrm{m}$ treated, $n=36 ; p=0.015$, Mann-Whitney $U$ test with Holm correction; Figs. $6 A, B$, Fig. $3 A)$ and the number of neuritebearing cells $(4.10 \pm 1.22 \%$ untreated, $n=$ 
Table 2. Total neurite length and percentages of n.b.c.s in SNS-gp130-/- cultures after leptin or NGF/leptin treatment

\begin{tabular}{lcllr}
\hline & Neurite length $(\mu \mathrm{m})$ & $p$ & \multicolumn{1}{c}{ n.b.c. } & \multicolumn{1}{c}{$p$} \\
\hline Ctrl & $169.13 \pm 36.43$ & & $6.21 \pm 1.54$ & \\
NGF & $346.06 \pm 34.58$ & $0.031^{a}$ & $18.28 \pm 2.03$ & $<0.000001^{a}$ \\
Leptin & $627.63 \pm 145.94$ & $0.031^{a}$ & $20.04 \pm 1.20$ & $<0.000001^{a}$ \\
& & & & $0.545725^{b}$ \\
NGF + leptin & $1589.62 \pm 148.63$ & $0.000006^{a}$ & $39.46 \pm 0.82$ & $<0.000001^{a}$ \\
& & $0.000005^{b}$ & & $<0.000001^{b}$ \\
& & $0.000004^{c}$ & & $0.000051^{c}$ \\
NGF + leptin + & $696.82 \pm 137.79$ & & $6.19 \pm 2.16$ & $0.965988^{a}$ \\
$1.5 \mu$ M Stattic & & & & \\
& & & & $0.000008^{b}$ \\
& & & & $0.000008^{c}$ \\
& & $0.0226^{d}$ & & $<0.000001^{d}$ \\
\hline
\end{tabular}

Mann-Whitney $U$ test with Holm correction or $\chi^{2}$ test.

${ }^{a}$ Comparison versus $\mathrm{Ctrl}$.

${ }^{b}$ Comparison versus NGF.

'Comparison versus leptin

${ }^{d}$ Comparison versus NGF + leptin.

305 vs $20.04 \pm 1.20 \%$ treated, $n=184 ; p=0.000001, \chi^{2}$ test; Fig. $6 B)$. Because the outgrowth response to NGF was impaired in $S N S-g p 130^{-1-}$ neurons, cultures from SNS- $g p 130^{-/-}$mice were stimulated with a combination of leptin $(100 \mathrm{ng} / \mathrm{ml})$ and NGF $(100 \mathrm{ng} / \mathrm{ml})$ for $20 \mathrm{~h}$. This treatment fully rescued NGF-mediated neurite outgrowth of $g p 130$-deficient neurons to the level of NGF-treated $g p 130^{f l f l}$ control neurons (Table 2; Fig. 6C,D). To prove that this response was STAT3-dependent, SNS-gp130-1neurons were cultured with NGF and leptin in the presence of Stattic inhibitor. This treatment fully reversed the rescue effect of leptin in SNS-gp130 ${ }^{-1-}$ cultures (Table 2; Fig. 6C). In the presence of the Stattic inhibitor only $6 \%$ of neurons had neurites compared with $39 \%$ of neurons treated with leptin and NGF in the absence of the inhibitor (Table 2; Fig. 6D). These results reveal that alternative STAT activation is effective at rescuing outgrowth of adult sensory neurons in response to the neurotrophin NGF in the absence of gp130.

\section{Discussion}

Peripheral nerve injury triggers a series of highly regulated cellular responses that imply regulation of neuroactive substances in neurons, macrophages, and Schwann cells. In the present study, we have studied the role of gp130, the receptor for group of cytokines, which are regulated and secreted after injury. We provide in vivo evidence for Nav1.8-positive adult sensory that after injury intrinsic neuronal expression of gp130 regulates functional recovery of thermal and mechanical sensitivity, as well as target tissue reinnervation.

Several previous reports have indicated a function of gp 130 ligands in axonal regrowth after injury (Hirota et al., 1996; Sendtner et al., 1997; Zhong et al., 1999; Cafferty et al., 2001; Shuto et al., 2001; Gardiner et al., 2002; Lara-Ramirez et al., 2008). However, gp130 itself is ubiquitously expressed and its cytokine ligands exert pleiotropic and often redundant responses on many different cell types. Therefore, in several in vivo scenarios it turned out to be difficult to assign cell-specific functions to individual gp130 ligands. One well described example of gp130 ligand redundancy in the nervous system is postnatal sympathetic neurotransmitter plasticity (for review, see Apostolova and Dechant, 2009). gp130 Cytokines including IL-6, LIF, CNTF, and others can trigger cholinergic differentiation of noradrenergic sympathetic neurons in neuronal culture. Surprisingly, mice carrying double or even triple mutations of the corresponding genes were not impaired in cholinergic differentiation in vivo (Rao et al., 1992). By contrast, conditional $D B H$-gp130 knock-out animals, which specifically lack gp130 in noradrenergic neurons, display the expected loss of the cholinergic sympathetic phenotype (Stanke et al., 2006). Analogous observations were also made with respect to the regulation of neuropeptides after axotomy in the mature peripheral nervous system. Several gp130 ligands are potent regulators of neuropeptides in sympathetic neurons in vitro. However, individual knock-outs of the gp130 ligands IL-6 and LIF did not show the corresponding in vivo phenotype (Corness et al., 1996; Sun and Zigmond, 1996; Murphy et al., 1999). Again, experiments with the conditional $D B H-g p 130$ mutant strain finally confirmed that gp130 cytokine-signaling is required for neuropeptide regulation following axotomy in adult sympathetic neurons (Habecker et al., 2009). Finally, a third study with the same conditional mutant demonstrated that the conditioning lesion response of sympathetic neurons also depends on neuronal gp130 and its ligands (Hyatt Sachs et al., 2010).

In view of these previous key findings in the sympathetic nervous system, we decided to study the effect of gp130 and its ligands on functional and morphological recovery of axons after injury in the peripheral sensory nervous system in a conditional gp130 mutant mouse strain. In this mouse model, the receptor is selectively targeted in nociceptor neurons expressing the NaV1.8 sodium channel. We identified a severe delay of functional recovery and cutaneous reinnervation after experimental nerve crush. These findings demonstrate that at least some of the nerve regeneration promoting effects of neuropoietic cytokines are mediated via gp130 expressed on neurons and are not indirectly via gp130bearing Schwann cells or macrophages. However, although functional recovery and morphological regeneration of sensory axons were delayed after sciatic nerve crush in our model, there was no general failure of sensory neuronal regeneration. The reasons for this and potential redundancies or compensatory effects in vivo remain to be explored.

To obtain insight in potential cellular mechanisms we used cultures of adult sensory neurons as an in vitro injury model. Corresponding well to our in vivo results, the number of neuritebearing DRG neurons, as well as the average neurite length, was significantly reduced in neurons lacking gp130. Interestingly, a reduction was observed in the presence as well as in the absence of added gp130 cytokines including HIL6, IL-6, CNTF, and LIF. Therefore, it is likely that gp130 has a basal level of activity in untreated cultures presumably due to the presence of endogenously expressed gp130 ligands. It is of note that in our mouse cell culture model IL-6 and the designer peptide HIL-6 were similarly efficient in increasing the neurite length in control neurons. This suggests that the soluble IL-6 receptor $\alpha$ subunit (sIL-6R) is not essential for neurite regeneration in the mouse. The capability of IL-6 to produce cellular effects in the absence of ligand binding sIL-6R in rat and mouse is currently controversially discussed (Obreja et al., 2002b, 2005; Cafferty et al., 2004; Cao et al., 2006).

An unexpected result of our study was that the prominent and well documented stimulating effect of NGF on neurite outgrowth in cultures of adult sensory neurons is reduced in the absence of gp130 (Lindsay, 1988). This factor is not known to bind to gp130 containing complexes, and our finding is not explained by alterations in the expression levels of the NGF receptors or reduced potential of NGF to activate the ERK pathway. Therefore, although the NGF signaling is intact at the level of the receptor, it cannot exert its full effect without basic levels of concomitant gp130 activity. Crosstalk between gp130 and NGF signaling ap- 
pears to be context-specific in neurons. Several studies on primary neurons reported opposing effects of gp130 cytokines and NGF. This includes for one the neuropeptide expression after axotomy in DRG and sympathetic SCG. And in the developing sympathetic nervous system, cholinergic differentiation is promoted by gp130 cytokines, whereas NGF stabilizes the noradrenergic phenotype (Brodski et al., 2002). With respect to neurite outgrowth, gp130 signaling has been reported to inhibit NGF in PC12 (Ng et al., 2003) but in adult sensory neuronal cultures CNTF and LIF, like NGF, stimulate outgrowth (Cafferty et al., 2001; Sango et al., 2008).

After ligand binding, the gp130 receptor activates receptor associated Janus kinases and recruits and phosphorylates transcription factors of the STAT family, in particular STAT1 and STAT3 (for review, see Heinrich et al., 1998). In our experiments, we identify STAT signaling as the intracellular mediator on which NGF and neuropoietic cytokines converge downstream of their signaling receptors.

Phosphorylation of STAT3 was significantly reduced in neurons lacking $g p 130$ in the presence, as well as in the absence, of added neuropoietic cytokines, confirming the presence of basal gp130 activation in untreated cultures. The observation that STAT inhibitor causes a reduction of outgrowth in cultures of all tested genotypes, demonstrates that gp130-dependent activation of STAT3 is important for regulation of neurite outgrowth in peripheral sensory neurons. Our results are consistent with reports that already had indicated that STAT3 has a critical role in the initiation phase of axonal outgrowth and in the early regeneration response (Bareyre et al., 2011; Ben-Yaakov et al., 2012). Consistent with these findings STAT signaling and in particular STAT3 phosphorylation is a close correlate of regeneration in adult DRG neurons. STAT activation in DRG was reported after PNS lesion but not CNS lesion (Schwaiger et al., 2000; Qiu et al., 2005). In axotomized DRG neurons in vivo, STAT phosphorylation occurs rapidly; it peaks after $6 \mathrm{~h}$ and remains elevated for weeks during regeneration. The JAK inhibitor AG490 blocks DRG outgrowth (Liu and Snider, 2001) in vitro and in vivo (Qiu et al., 2005). In gain of function experiments, it could be shown that hyperactivation of Stat 3 by overexpression increases sprouting after spinal cord injury (Bareyre et al., 2011).

Furthermore, STAT3 was picked up in two recent screens identifying transcription factors regulated during regeneration (Michaelevski et al., 2010; Smith et al., 2011). Interestingly STAT3 seems to have transcription-independent local effects in degenerating axons of motoneurons where it modifies microtubule stability via interaction with stathmin (Selvaraj et al., 2012).

With respect to STAT activation, NGF has been described to inhibit axotomy induced activation of STAT3 (Rajan et al., 1998), but to stimulate STAT3 in PC12 and embryonic cortical neurons (Ng et al., 2006; Zhou and Too, 2011) by, as yet, undefined mechanisms. STAT3 phosphorylation occurs in DRGs and sciatic nerve upon NGF injection in rats (Donnerer et al., 2005). We found that NGF treatment causes slightly elevated levels of pSTAT3 in control cultures and a reduction in phopsho-STAT3 (but not total STAT3 protein) was associated with reduced NGF stimulated neurite outgrowth in gp130-deficient neurons. In our experiments with wild-type neurons, the JAK inhibitor JAKI and, in particular, the STAT inhibitor Stattic not only reduced neurite outgrowth in response to gp130 ligands but also significantly impaired the effect of NGF. Stattic seems to be more selective for STAT3 over other members of the STAT family (Schust et al., 2006). However, other STATs are also activated after injury and may possibly contribute to the regeneration process (Dziennis and Alkayed, 2008). The impairment in NGF-mediated neurite outgrowth in gp130-deficient neurons was rescued when STAT3 was activated by a gp130-independent mechanism via leptin.

Together, the present study demonstrates that gp130-dependent activation of STATs in axotomized adult sensory neurons integrates neurite outgrowth promoting extracellular stimuli including gp130 cytokines and the neurotrophin NGF.

\section{References}

Agarwal N, Pacher P, Tegeder I, Amaya F, Constantin CE, Brenner GJ, Rubino T, Michalski CW, Marsicano G, Monory K, Mackie K, Marian C, Batkai S, Parolaro D, Fischer MJ, Reeh P, Kunos G, Kress M, Lutz B, Woolf CJ, Kuner R (2007) Cannabinoids mediate analgesia largely via peripheral type 1 cannabinoid receptors in nociceptors. Nat Neurosci 10:870-879. CrossRef Medline

Agarwal N, Offermanns S, Kuner R (2004) Conditional gene deletion in primary nociceptive neurons of trigeminal ganglia and dorsal root ganglia. Genesis 38:122-129. CrossRef Medline

Andratsch M, Mair N, Constantin CE, Scherbakov N, Benetti C, Quarta S, Vogl C, Sailer CA, Uceyler N, Brockhaus J, Martini R, Sommer C, Zeilhofer HU, Müller W, Kuner R, Davis JB, Rose-John S, Kress M (2009) A key role for gp130 expressed on peripheral sensory nerves in pathological pain. J Neurosci 29:13473-13483. CrossRef Medline

Aoki Y, Takahashi Y, Ohtori S, Moriya H, Takahashi K (2004) Distribution and immunocytochemical characterization of dorsal root ganglion neurons innervating the lumbar intervertebral disc in rats: a review. Life Sci 74:2627-2642. CrossRef Medline

Apostolova G, Dechant G (2009) Development of neurotransmitter phenotypes in sympathetic neurons. Auton Neurosci 151:30-38. CrossRef Medline

Bareyre FM, Garzorz N, Lang C, Misgeld T, Büning H, Kerschensteiner M (2011) In vivo imaging reveals a phase-specific role of STAT3 during central and peripheral nervous system axon regeneration. Proc Natl Acad Sci U S A 108:6282-6287. CrossRef Medline

Ben-Yaakov K, Dagan SY, Segal-Ruder Y, Shalem O, Vuppalanchi D, Willis DE, Yudin D, Rishal I, Rother F, Bader M, Blesch A, Pilpel Y, Twiss JL, Fainzilber M (2012) Axonal transcription factors signal retrogradely in lesioned peripheral nerve. EMBO J 31:1350-1363. CrossRef Medline

Betz UA, Bloch W, van den Broek M, Yoshida K, Taga T, Kishimoto T, Addicks K, Rajewsky K, Müller W (1998) Postnatally induced inactivation of gp130 in mice results in neurological, cardiac, hematopoietic, immunological, hepatic, and pulmonary defects. J Exp Med 188:19551965. CrossRef Medline

Bosse F (2012) Extrinsic cellular and molecular mediators of peripheral axonal regeneration. Cell Tissue Res 349:5-14. CrossRef Medline

Brodski C, Schaubmar A, Dechant G (2002) Opposing functions of GDNF and NGF in the development of cholinergic and noradrenergic sympathetic neurons. Mol Cell Neurosci 19:528-538. CrossRef Medline

Cafferty WB, Gardiner NJ, Gavazzi I, Powell J, McMahon SB, Heath JK, Munson J, Cohen J, Thompson SW (2001) Leukemia inhibitory factor determines the growth status of injured adult sensory neurons. J Neurosci 21:7161-7170. Medline

Cafferty WB, Gardiner NJ, Das P, Qiu J, McMahon SB, Thompson SW (2004) Conditioning injury-induced spinal axon regeneration fails in interleukin-6 knock-out mice. J Neurosci 24:4432-4443. CrossRef Medline

Cao Z, Gao Y, Bryson JB, Hou J, Chaudhry N, Siddiq M, Martinez J, Spencer T, Carmel J, Hart RB, Filbin MT (2006) The cytokine interleukin-6 is sufficient but not necessary to mimic the peripheral conditioning lesion effect on axonal growth. J Neurosci 26:5565-5573. CrossRef Medline

Chaplan SR, Bach FW, Pogrel JW, Chung JM, Yaksh TL (1994) Quantitative assessment of tactile allodynia in the rat paw. J Neurosci Methods 53:5563. CrossRef Medline

Corness J, Shi TJ, Xu ZQ, Brulet P, Hökfelt T (1996) Influence of leukemia inhibitory factor on galanin/GMAP and neuropeptide $\mathrm{Y}$ expression in mouse primary sensory neurons after axotomy. Exp Brain Res 112:79-88. Medline

De Koning P, Brakkee JH, Gispen WH (1986) Methods for producing a reproducible crush in the sciatic and tibial nerve of the rat and rapid and precise testing of return of sensory function: beneficial effects of melanocortins. J Neurol Sci 74:237-246. CrossRef Medline 
Dixon WJ (1980) Efficient analysis of experimental observations. Annu Rev Pharmacol Toxicol 20:441-462. CrossRef Medline

Donnerer J, Liebmann I, Schicho R (2005) ERK and STAT3 phosphorylation in sensory neurons during capsaicin-induced impairment and nerve growth factor treatment. Pharmacology 75:116-121. CrossRef Medline

Dziennis S, Alkayed NJ (2008) Role of signal transducer and activator of transcription 3 in neuronal survival and regeneration. Rev Neurosci 19: 341-361. CrossRef Medline

Ernst M, Jenkins BJ (2004) Acquiring signalling specificity from the cytokine receptor gp130. Trends Genet 20:23-32. CrossRef Medline

Fischer M, Goldschmitt J, Peschel C, Brakenhoff JP, Kallen KJ, Wollmer A, Grötzinger J, Rose-John S (1997) I. A bioactive designer cytokine for human hematopoietic progenitor cell expansion. Nat Biotechnol 15:142145. CrossRef Medline

Gardiner NJ, Cafferty WB, Slack SE, Thompson SW (2002) Expression of gp130 and leukaemia inhibitory factor receptor subunits in adult rat sensory neurones: regulation by nerve injury. J Neurochem 83:100-109. CrossRef Medline

Gaudet AD, Popovich PG, Ramer MS (2011) Wallerian degeneration: gaining perspective on inflammatory events after peripheral nerve injury. J Neuroinflammation 8:110. CrossRef Medline

Gölz G, Uhlmann L, Lüdecke D, Markgraf N, Nitsch R, Hendrix S (2006) The cytokine/neurotrophin axis in peripheral axon outgrowth. Eur J Neurosci 24:2721-2730. CrossRef Medline

Habecker BA, Sachs HH, Rohrer H, Zigmond RE (2009) The dependence on gp130 cytokines of axotomy induced neuropeptide expression in adult sympathetic neurons. Dev Neurobiol 69:392-400. CrossRef Medline

Hargreaves K, Dubner R, Brown F, Flores C, Joris J (1988) A new and sensitive method for measuring thermal nociception in cutaneous hyperalgesia. Pain 32:77-88. CrossRef Medline

Heinrich PC, Behrmann I, Müller-Newen G, Schaper F, Graeve L (1998) Interleukin-6-type cytokine signalling through the gp130/Jak/STAT pathway. Biochem J 334:297-314. Medline

Heinrich PC, Behrmann I, Haan S, Hermanns HM, Müller-Newen G, Schaper F (2003) Principles of interleukin (IL)-6-type cytokine signalling and its regulation. Biochem J 374:1-20. CrossRef Medline

Hibi M, Murakami M, Saito M, Hirano T, Taga T, Kishimoto T (1990) Molecular cloning and expression of an IL-6 signal transducer, gp130. Cell 63:1149-1157. CrossRef Medline

Hirota H, Kiyama H, Kishimoto T, Taga T (1996) Accelerated nerve regeneration in mice by upregulated expression of interleukin (IL) 6 and IL-6 receptor after trauma. J Exp Med 183:2627-2634. CrossRef Medline

Hyatt Sachs H, Rohrer H, Zigmond RE (2010) The conditioning lesion effect on sympathetic neurite outgrowth is dependent on gp130 cytokines. Exp Neurol 223:516-522. CrossRef Medline

Jones SA, Scheller J, Rose-John S (2011) Therapeutic strategies for the clinical blockade of IL-6/gp130 signaling. J Clin Invest 121:3375-3383. CrossRef Medline

Kaplan DR, Hempstead BL, Martin-Zanca D, Chao MV, Parada LF (1991) The trk proto-oncogene product: a signal transducing receptor for nerve growth factor. Science 252:554-558. CrossRef Medline

Klein R, Parada LF, Coulier F, Barbacid M (1989) trkB, a novel tyrosine protein kinase receptor expressed during mouse neural development. EMBO J 8:3701-3709. Medline

Klein R, Nanduri V, Jing SA, Lamballe F, Tapley P, Bryant S, Cordon-Cardo C, Jones KR, Reichardt LF, Barbacid M (1991) The trkB tyrosine protein kinase is a receptor for brain-derived neurotrophic factor and neurotrophin-3. Cell 66:395-403. CrossRef Medline

Klein R, Lamballe F, Bryant S, Barbacid M (1992) The trkB tyrosine protein kinase is a receptor for neurotrophin-4. Neuron 8:947-956. CrossRef Medline

Kopf M, Baumann H, Freer G, Freudenberg M, Lamers M, Kishimoto T, Zinkernagel R, Bluethmann H, Köhler G (1994) Impaired immune and acute-phase responses in interleukin-6-deficient mice. Nature 368:339342. CrossRef Medline

Lamballe F, Klein R, Barbacid M (1991) trkC, a new member of the trk family of tyrosine protein kinases, is a receptor for neurotrophin-3. Cell 66:967-979. CrossRef Medline

Lara-Ramírez R, Segura-Anaya E, Martínez-Gómez A, Dent MA (2008) Expression of interleukin-6 receptor alpha in normal and injured rat sciatic nerve. Neuroscience 152:601-608. CrossRef Medline
Levi-Montalcini R (1952) Effects of mouse tumor transplantation on the nervous system. Ann N Y Acad Sci 55:330-344. CrossRef Medline

Levi-Montalcini R (1987) The nerve growth factor 35 years later. Science 237:1154-1162. CrossRef Medline

Lindfors PH, Võikar V, Rossi J, Airaksinen MS (2006) Deficient nonpeptidergic epidermis innervation and reduced inflammatory pain in glial cell line-derived neurotrophic factor family receptor alpha2 knock-out mice. J Neurosci 26:1953-1960. CrossRef Medline

Lindsay RM (1988) Nerve growth factors (NGF, BDNF) enhance axonal regeneration but are not required for survival of adult sensory neurons. J Neurosci 8:2394-2405. Medline

Liu RY, Snider WD (2001) Different signaling pathways mediate regenerative versus developmental sensory axon growth. J Neurosci 21:RC164. Medline

März P, Herget T, Lang E, Otten U, Rose-John S (1997) Activation of gp130 by IL-6/soluble IL-6 receptor induces neuronal differentiation. Eur J Neurosci 9:2765-2773. CrossRef Medline

März P, Cheng JG, Gadient RA, Patterson PH, Stoyan T, Otten U, Rose-John S (1998) Sympathetic neurons can produce and respond to interleukin 6. Proc Natl Acad Sci U S A 95:3251-3256. CrossRef Medline

Meijering E, Jacob M, Sarria JC, Steiner P, Hirling H, Unser M (2004) Design and validation of a tool for neurite tracing and analysis in fluorescence microscopy images. Cytometry A 58:167-176. CrossRef Medline

Melemedjian OK, Asiedu MN, Tillu DV, Peebles KA, Yan J, Ertz N, Dussor GO, Price TJ (2010) IL-6- and NGF-induced rapid control of protein synthesis and nociceptive plasticity via convergent signaling to the eIF4F complex. J Neurosci 30:15113-15123. CrossRef Medline

Michaelevski I, Segal-Ruder Y, Rozenbaum M, Medzihradszky KF, Shalem O, Coppola G, Horn-Saban S, Ben-Yaakov K, Dagan SY, Rishal I, Geschwind DH, Pilpel Y, Burlingame AL, Fainzilber M (2010) Signaling to transcription networks in the neuronal retrograde injury response. Sci Signal 3:ra53. CrossRef Medline

Murphy PG, Grondin J, Altares M, Richardson PM (1995) Induction of interleukin-6 in axotomized sensory neurons. J Neurosci 15:5130-5138. Medline

Murphy PG, Ramer MS, Borthwick L, Gauldie J, Richardson PM, Bisby MA (1999) Endogenous interleukin-6 contributes to hypersensitivity to cutaneous stimuli and changes in neuropeptides associated with chronic nerve constriction in mice. Eur J Neurosci 11:2243-2253. CrossRef Medline

Ng YP, He W, Ip NY (2003) Leukemia inhibitory factor receptor signaling negatively modulates nerve growth factor-induced neurite outgrowth in PC12 cells and sympathetic neurons. J Biol Chem 278:38731-38739. CrossRef Medline

Ng YP, Cheung ZH, Ip NY (2006) STAT3 as a downstream mediator of Trk signaling and functions. J Biol Chem 281:15636-15644. CrossRef Medline

Obreja O, Rathee PK, Lips KS, Distler C, Kress M (2002a) IL-1 beta potentiates heat-activated currents in rat sensory neurons: involvement of IL1RI, tyrosine kinase, and protein kinase C. FASEB J 16:1497-1503. CrossRef Medline

Obreja O, Schmelz M, Poole S, Kress M (2002b) Interleukin-6 in combination with its soluble IL-6 receptor sensitises rat skin nociceptors to heat, in vivo. Pain 96:57-62. CrossRef Medline

Obreja O, Biasio W, Andratsch M, Lips KS, Rathee PK, Ludwig A, Rose-John S, Kress M (2005) Fast modulation of heat-activated ionic current by proinflammatory interleukin 6 in rat sensory neurons. Brain 128:16341641. CrossRef Medline

Pedranzini L, Dechow T, Berishaj M, Comenzo R, Zhou P, Azare J, Bornmann W, Bromberg J (2006) Pyridone 6, a pan-Janus-activated kinase inhibitor, induces growth inhibition of multiple myeloma cells. Cancer Res 66:9714-9721. CrossRef Medline

Qiu J, Cafferty WB, McMahon SB, Thompson SW (2005) Conditioning injury-induced spinal axon regeneration requires signal transducer and activator of transcription 3 activation. J Neurosci 25:1645-1653. CrossRef Medline

Quarta S, Vogl C, Constantin CE, Üceyler N, Sommer C, Kress M (2011) Genetic evidence for an essential role of neuronally expressed IL-6 signal transducer gp130 in the induction and maintenance of experimentally induced mechanical hypersensitivity in vivo and in vitro. Mol Pain 7:73. CrossRef Medline

Rajan P, Gearan T, Fink JS (1998) Leukemia inhibitory factor and NGF 
regulate signal transducers and activators of transcription activation in sympathetic ganglia: convergence of cytokine- and neurotrophinsignaling pathways. Brain Res 802:198-204. CrossRef Medline

Rao MS, Patterson PH, Landis SC (1992) Multiple cholinergic differentiation factors are present in footpad extracts: comparison with known cholinergic factors. Development 116:731-744. Medline

Saadat S, Sendtner M, Rohrer H (1989) Ciliary neurotrophic factor induces cholinergic differentiation of rat sympathetic neurons in culture. J Cell Biol 108:1807-1816. CrossRef Medline

Sango K, Yanagisawa H, Komuta Y, Si Y, Kawano H (2008) Neuroprotective properties of ciliary neurotrophic factor for cultured adult rat dorsal root ganglion neurons. Histochem Cell Biol 130:669-679. CrossRef Medline

Schäfer KH, Mestres P, März P, Rose-John S (1999) The IL-6/sIL-6R fusion protein hyper-IL-6 promotes neurite outgrowth and neuron survival in cultured enteric neurons. J Interferon Cytokine Res 19:527-532. CrossRef Medline

Schust J, Sperl B, Hollis A, Mayer TU, Berg T (2006) Stattic: a smallmolecule inhibitor of STAT3 activation and dimerization. Chem Biol 13:1235-1242. CrossRef Medline

Schwaiger FW, Hager G, Schmitt AB, Horvat A, Hager G, Streif R, Spitzer C, Gamal S, Breuer S, Brook GA, Nacimiento W, Kreutzberg GW (2000) Peripheral but not central axotomy induces changes in Janus kinases (JAK) and signal transducers and activators of transcription (STAT). Eur J Neurosci 12:1165-1176. CrossRef Medline

Selvaraj BT, Frank N, Bender FL, Asan E, Sendtner M (2012) Local axonal function of STAT3 rescues axon degeneration in the pmn model of motoneuron disease. J Cell Biol 199:437-451. CrossRef Medline

Sendtner M, Götz R, Holtmann B, Thoenen H (1997) Endogenous ciliary neurotrophic factor is a lesion factor for axotomized motoneurons in adult mice. J Neurosci 17:6999-7006. Medline

Shuto T, Horie H, Hikawa N, Sango K, Tokashiki A, Murata H, Yamamoto I, Ishikawa Y (2001) IL-6 up-regulates CNTF mRNA expression and enhances neurite regeneration. Neuroreport 12:1081-1085. CrossRef Medline

Skaper SD (2008) The biology of neurotrophins, signalling pathways, and functional peptide mimetics of neurotrophins and their receptors. CNS Neurol Disord Drug Targets 7:46-62. CrossRef Medline

Smith JA, Das A, Ray SK, Banik NL (2012) Role of pro-inflammatory cytokines released from microglia in neurodegenerative diseases. Brain Res Bull 87:10-20. CrossRef Medline

Smith RP, Lerch-Haner JK, Pardinas JR, Buchser WJ, Bixby JL, Lemmon VP (2011) Transcriptional profiling of intrinsic PNS factors in the postnatal mouse. Mol Cell Neurosci 46:32-44. CrossRef Medline

Spooren A, Kolmus K, Laureys G, Clinckers R, De Keyser J, Haegeman G,
Gerlo S (2011) Interleukin-6, a mental cytokine. Brain Res Rev 67:157183. CrossRef Medline

Stanke M, Duong CV, Pape M, Geissen M, Burbach G, Deller T, Gascan H, Otto C, Parlato R, Schütz G, Rohrer H (2006) Target-dependent specification of the neurotransmitter phenotype: cholinergic differentiation of sympathetic neurons is mediated in vivo by gp 130 signaling. Development 133:141-150. CrossRef Medline

Sun Y, Zigmond RE (1996) Involvement of leukemia inhibitory factor in the increases in galanin and vasoactive intestinal peptide mRNA and the decreases in neuropeptide $\mathrm{Y}$ and tyrosine hydroxylase mRNA in sympathetic neurons after axotomy. J Neurochem 67:1751-1760. Medline

Tedeschi A (2011) Tuning the orchestra: transcriptional pathways controlling axon regeneration. Front Mol Neurosci 4:60. CrossRef Medline

Terenghi G (1999) Peripheral nerve regeneration and neurotrophic factors. J Anat 194:1-14. CrossRef Medline

Thompson JE, Cubbon RM, Cummings RT, Wicker LS, Frankshun R, Cunningham BR, Cameron PM, Meinke PT, Liverton N, Weng Y, DeMartino JA (2002) Photochemical preparation of a pyridone containing tetracycle: a Jak protein kinase inhibitor. Bioorg Med Chem Lett 12:1219_ 1223. CrossRef Medline

Waetzig V, Zhao Y, Herdegen T (2006) The bright side of JNKsmultitalented mediators in neuronal sprouting, brain development and nerve fiber regeneration. Prog Neurobiol 80:84-97. CrossRef Medline

Wilms H, Zecca L, Rosenstiel P, Sievers J, Deuschl G, Lucius R (2007) Inflammation in Parkinson's diseases and other neurodegenerative diseases: cause and therapeutic implications. Curr Pharm Des 13:1925-1928. CrossRef Medline

Yamashita T, Tucker KL, Barde YA (1999) Neurotrophin binding to the p75 receptor modulates Rho activity and axonal outgrowth. Neuron 24:585593. CrossRef Medline

Zhong J, Dietzel ID, Wahle P, Kopf M, Heumann R (1999) Sensory impairments and delayed regeneration of sensory axons in interleukin-6deficient mice. J Neurosci 19:4305-4313. Medline

Zhou L, Too HP (2011) Mitochondrial localized STAT3 is involved in NGF induced neurite outgrowth. PLoS One 6:e21680. CrossRef Medline

Zigmond RE (2012) gp130 cytokines are positive signals triggering changes in gene expression and axon outgrowth in peripheral neurons following injury. Front Mol Neurosci 4:62. CrossRef Medline

Zimmermann M (1983) Ethical guidelines for investigations of experimental pain in conscious animals. Pain 16:109-110. CrossRef Medline

Zylka MJ, Rice FL, Anderson DJ (2005) Topographically distinct epidermal nociceptive circuits revealed by axonal tracers targeted to Mrgprd. Neuron 45:17-25. CrossRef Medline 